\title{
Fast Synaptic Vesicle Reuse Slows the Rate of Synaptic Depression in the CA1 Region of Hippocampus
}

\author{
Mert Ertunc, Yildirim Sara, ChiHye Chung, Deniz Atasoy, Tuhin Virmani, and Ege T. Kavalali \\ Center for Basic Neuroscience and Department of Physiology, The University of Texas Southwestern Medical Center, Dallas, Texas 75390-9111
}

During short-term synaptic depression, neurotransmission rapidly decreases in response to repetitive action potential firing. Here, by blocking the vacuolar ATPase, alkalinizing the extracellular $\mathrm{pH}$, or exposing hippocampal slices to $\mathrm{pH}$ buffers, we impaired neurotransmitter refilling, and electrophysiologically tested the role of vesicle reuse in synaptic depression. Under all conditions, synapses onto hippocampal CA1 pyramidal cells showed faster depression with increasing stimulation frequencies. At $20 \mathrm{~Hz}$, compromising neurotransmitter refilling increased depression within $300 \mathrm{~ms}$ reaching completion within $2 \mathrm{~s}$, suggesting a minimal contribution of reserve vesicles to neurotransmission. In contrast, at $1 \mathrm{~Hz}$, depression emerged gradually and became significant within $100 \mathrm{~s}$. Moreover, the depression induced by $\mathrm{pH}$ buffers was reversible with a similar frequency dependence, suggesting that the frequency-dependent increase in depression was caused by impairment of rapid synaptic vesicle reuse. These results indicate that synaptic vesicle trafficking impacts the kinetics of short-term synaptic plasticity at an extremely rapid time scale.

Key words: synaptic vesicle recycling; hippocampal slice; short term synaptic depression; vesicle reacidification; endocytosis; CA1; Schaffer collateral

\section{Introduction}

Synaptic vesicle recycling is essential to sustain neurotransmission during activity in central synapses (Sudhof, 2000; Harata et al., 2001). However, it is currently a matter of debate as to whether synaptic vesicle recycling becomes rate limiting on a rapid time scale during physiologically relevant forms of activity in the brain (Pyle et al., 2000; Sara et al., 2002; Fernandez-Alfonso and Ryan, 2004; Li et al., 2005; Zenisek, 2005; Virmani et al., 2006). One caveat is that these studies have difficulty in distinguishing the contribution and timing of vesicle reuse to neurotransmitter release during activity. Most studies have relied on optical techniques using styryl dyes (Betz and Bewick, 1992) and synaptopHluorin $(\mathrm{spH})$ [a fusion construct of $\mathrm{pH}$-sensitive green fluorescent protein (GFP) and synaptic vesicle protein synaptobrevin/vesicle-associated membrane protein (VAMP)] (Miesenbock et al., 1998) to track vesicle use history and discern exocytosis and endocytosis. However, the direct relationship of these purely optical signals to the kinetics of electrical transmission has been difficult to establish because they rely on several

\footnotetext{
Received April 13, 2006; revised Dec. 4, 2006; accepted Dec. 5, 2006.

This work was supported by National Institute of Mental Health Grant MH068437 to E.T.K. E.T.K. is an Established Investigator of the American Heart Association. We thank Drs. K. Huber, L. Monteggia, J. Gibson, and J. Sun for helpful discussions and for critically reading this manuscript. We also thank Dr. V. N. Murthy for the gift of spH21 transgenic mice, Dr. Jef K. De Brabander for the gift of salicylihalamide A, and Drs. Y. Zhu and C. F. Stevens for the gift of synaptophysin-pHluorin construct. We are grateful to Mr. Sanket Kale for his technical assistance during this project.

Correspondence should be addressed to Dr. Ege T. Kavalali, Center for Basic Neuroscience, The University of Texas, Southwestern Medical Center, 5323 Harry Hines Boulevard, Dallas, TX 75390-9111. E-mail: Ege.Kavalali@UTSouthwestern.edu.

Y. Sara's present address: Department of Pharmacology, Hacettepe University Faculty of Medicine, Sihhiye 06100, Ankara, Turkey.

D01:10.1523/JNEUROSCI.4051-06.2007

Copyright $\odot 2007$ Society for Neuroscience $\quad$ 0270-6474/07/270341-14\$15.00/0
}

complex features of these probes to monitor vesicle reuse. In the case of styryl dyes, postfusional retention of slowly departitioning FM dyes could report reuse of dye-containing vesicles (Klingauf et al., 1998; Pyle et al., 2000; Aravanis et al., 2003; Richards et al., 2005). For experiments with synaptophluorin, the postendocytic trafficking of synaptobrevin/VAMP has been used as a read out for the kinetics of vesicle trafficking after fusion (Li and Murthy, 2001; Sankaranarayanan and Ryan, 2001; Li et al., 2005). These experiments, using optical tools, consistently support the premise that synaptic vesicle exocytosis and endocytosis are tightly coupled processes. However, in most cases, their ability to monitor synaptic vesicle reuse and reavailability of vesicles for consequent rounds of fusion after endocytosis have relied on the somewhat difficult comparison of presynaptic optical signals to postsynaptic electrical recordings. This comparison is complicated by the distinct physical nature, origin, and complex kinetic correspondence of the two signals (Betz and Bewick, 1992, 1993; Sara et al., 2002; Li et al., 2005; Virmani et al., 2006).

In this study, we used an electrophysiological approach that took advantage of the neurotransmitter refilling process into vesicles. Using blockers of vacuolar ATPase (v-ATPase), as well as small $\mathrm{pH}$ buffers that can be loaded into endocytosing vesicles, we impaired synaptic vesicle reacidification and neurotransmitter refilling and then tested the dependence of short-term synaptic depression on synaptic vesicle reuse. Electrophysiological detection of neurotransmission in such a setting has several advantages such as its millisecond time resolution, direct monitoring of the kinetics of neurotransmission, and its applicability to complex tissues and neural circuitry from which optical signals are harder to detect over long periods. Under these conditions, we found that there was a use-dependent increase in the rate of synaptic depression in the CA1 region of hippocampal slices. This effect 
was frequency dependent as higher stimulation frequencies resulted in an earlier onset of vesicle reuse. These findings provide evidence for the presence of a very fast pathway for vesicle reuse in central synapses and reveal its impact on short-term synaptic plasticity.

\section{Materials and Methods}

\section{Hippocampal slice preparation}

Hippocampal slices were obtained from 12- to 21-d-old Sprague Dawley rats. After Nembutal ( $20 \mathrm{mg} / \mathrm{kg}$; Abbott Laboratories, Abbott Park, IL) anesthesia, rats were rapidly decapitated, hippocampi were removed, and transverse slices $(400 \mu \mathrm{M})$ were cut in oxygenated, ice-cold dissection [low $\mathrm{Ca}^{2+} / \mathrm{high} \mathrm{Mg}^{2+}$ artificial CSF (ACSF)] solution using a Vibratome (St. Louis, MO) and incubated at $34^{\circ} \mathrm{C}$ for $30 \mathrm{~min}$ and then at room temperature $\left(24-27^{\circ} \mathrm{C}\right)$. Slices were maintained under these conditions at least $60 \mathrm{~min}$ before the start of experimentation. The ACSF contained the following (in mM): $124 \mathrm{NaCl}, 5 \mathrm{KCl}, 12 \mathrm{NaH}_{2} \mathrm{PO}_{4}, 26 \mathrm{NaHCO}_{3}, 10$ D-glucose, $2 \mathrm{CaCl}_{2}$, and $1 \mathrm{MgCl}_{2}$ was gassed with $95 \% \mathrm{O}_{2}$ and $5 \% \mathrm{CO}_{2}$. For electrophysiological experiments, after making a cut between the CA1 and CA3 regions, individual slices were transferred to the recording chamber on the stage of an upright microscope (E600FN; Nikon, Tokyo, Japan). During experiments, slices were submerged in ACSF, which was continuously exchanged by gravity-driven superfusion system with a flow rate of $1-3 \mathrm{ml} / \mathrm{min}$. Experiments were performed at room temperature. Neurons in slices were visualized through an upright microscope using a water-immersion objective ( 0.75 numerical aperture and $1.7 \mathrm{~mm}$ working distance) and differential interference contrast optics.

\section{Electrophysiology in hippocampal slices}

Electrophysiological recordings were performed in the whole-cell voltage-clamp configuration on the neurons in the pyramidal cell layer of area CA1 of hippocampus. Patch electrodes were fabricated from borosilicate glass capillaries (Warner Instruments, Hamden, CT) with a Flaming/Brown model P-97 micropipette puller (Sutter Instruments, Novato, $\mathrm{CA})$. Pipettes had a resistance of 3-6 $\mathrm{M} \Omega$ when filled with the internal pipette solution that contained the following (in $\mathrm{mm}$ ): $110 \mathrm{~K}$-gluconate, $20 \mathrm{KCl}, 10 \mathrm{NaCl}, 10$ HEPES, 0.6 EGTA, $4 \mathrm{Mg}$-ATP, $0.3 \mathrm{GTP}, 10$ lidocaine $\mathrm{N}$-ethyl bromide (QX-314), and buffered to $\mathrm{pH} 7.2-7.3$ with $\mathrm{CsOH}$ (280-290 mOsm). Recordings were obtained with an Axopatch-200B patch-clamp amplifier (Molecular Devices, Union City, CA). The membrane potential $(\mathrm{Vm})$ was held at $-70 \mathrm{mV}$. Fast and slow capacitances were neutralized. No series resistance (Rs) compensation was used during the experiments. In the whole-cell configuration, Rs ranged between 5 and $15 \mathrm{M} \Omega$, and experiments in which Rs varied $\geq 20 \%$ within a recording session were discarded. In all experiments, voltage errors were $<10 \mathrm{mV}$. Signals were low-pass filtered at $2 \mathrm{kHz}$, digitized at $10 \mathrm{kHz}$, and fed to a personal computer through a Digidata $1322 \mathrm{~A}$ interface board (Molecular Devices). The Clampex 9.0 and Clampfit 9.0 software (Molecular Devices) were used for data display, acquisition, and storage. Pharmacologically isolated EPSCs and IPSCs were evoked by stimulation of the Schaffer collateral (SC) fibers via concentric bipolar tungsten electrodes, which were placed under visual guidance in the stratum radiatum near the border of the CA1 pyramidal neurons $\sim 200 \mu \mathrm{m}$ from the wholecell electrode and the recorded cell. Constant-current pulses $(200 \mu \mathrm{s}$ duration; $10-100 \mu \mathrm{A}$ amplitude) were applied through a stimulus isolation unit (A365; WPI Sarasota, FL) driven by a dual-channel stimulator (Grass S88; Grass Instruments, Quincy, MA). To record and isolate miniature and evoked IPSCs, ionotropic glutamate receptor antagonist 6-cyano-7-nitroquinoxaline-2,3-dione (CNQX; $10 \mu \mathrm{M}$; Sigma, St. Louis, $\mathrm{MO}$ ), and aminophosphonopentanoic acid (AP-5; $50 \mu \mathrm{M}$; Sigma) were added to the bath solution. In the experiments at which non-NMDA EPSCs aimed to be isolated and recorded, picrotoxin (PTX; $50 \mu \mathrm{M}$; Sigma) and AP-5 were added to the bath solution.

\section{Electrophysiology in dissociated hippocampal cultures}

Synaptic responses were recorded from pyramidal cells using a whole-cell configuration of the patch-clamp technique. Data were acquired using an Axopatch 200B amplifier and Clampex 9.0 software. Recordings were filtered at $2 \mathrm{kHz}$ and sampled at $200 \mu$ s. The pipette internal solution included the following (in mM): $115 \mathrm{Cs}-\mathrm{MeSO}_{3}, 10 \mathrm{CsCl}, 5 \mathrm{NaCl}, 10$ HEPES, 0.6 EGTA, 20 tetraethylammonium-Cl, 4 Mg-ATP, $0.3 \mathrm{Na}_{3} \mathrm{GTP}$, and 10 lidocaine $N$-ethyl bromide, $\mathrm{pH} 7.35,300 \mathrm{mOsm}$.

\section{Drug treatments}

Folimycin treatment. Folimycin (Calbiochem, La Jolla, CA) was dissolved in dimethyl sulfoxide (DMSO) and $80 \mu \mathrm{M}$ of stock solution was prepared and preserved at $-20^{\circ} \mathrm{C}$. The drug was diluted in ACSF on the day of use. Final DMSO concentration was lower than $0.1 \%$. The drug was added to regular ACSF at a final concentration of $67 \mathrm{~nm}$ and slices were perfused with the solution for $10 \mathrm{~min}$ at the recording chamber and evoked responses were recorded thereafter. In the case of miniature EPSC and IPSC recordings, CA1 neurons were patched and clamped at $-70 \mathrm{mV}$, spontaneous events were recorded in the presence of $1 \mu \mathrm{M}$ TTX during a 10 min perfusion period with folimycin $(67 \mathrm{nM})$ containing ACSF, in 2 min intervals. In contrast to dissociated cultures, hippocampal slices show no spontaneous network activity; therefore, presence or absence of TTX does not make a significant difference. Here, it is important to note that folimycin substantially loses its effectiveness within hours at room temperature presumably because of its sensitivity to temperature and light.

Salicylihalamide A treatment. Salicylihalamide A was added directly to ACSF in which the final concentration was $10 \mathrm{~nm}$. Slices were perfused with the drug continuously and recordings were made immediately after 10 min of perfusion with ACSF containing salicylihalamide A. The drug was a generous gift from Dr. Jef K. De Brabander (University of Texas Southwestern Medical Center, Dallas, TX).

\section{Alkaline and acidic $p H$ experiments}

To achieve extracellular alkaline $\mathrm{pH}$, the bicarbonate buffer was increased to $40 \mathrm{~mm}$ and the change in $\mathrm{NaHCO}_{3}$ concentration was balanced by equimolar concentration of $\mathrm{NaCl}$. Final $\mathrm{pH}$ was adjusted to $\mathrm{pH} 9$ by adding $<1 \mathrm{~mm} \mathrm{NaOH}$ into oxygenated ACSF. Rest of the ACSF ionic composition was the same as the ones used in the other set of experiments. Osmolarity was $300 \pm 2 \mathrm{mOsm}$ at this condition. The $\mathrm{pH}$ of the perfusion solution was checked at the beginning and at the end of the experiments. To maintain acidic extracellular $\mathrm{pH}$, several drops of concentrated $\mathrm{HCl}$ were added to regular ACSF to adjust the $\mathrm{pH}$ (5.5 or 6.5). ACSF osmolarity was not affected by $\mathrm{HCl}$ addition.

\section{$\mathrm{NH}_{4} \mathrm{Cl}$ experiments}

For this set of experiments, $5 \mathrm{~mm}$ of ammonium chloride $\left(\mathrm{NH}_{4} \mathrm{Cl}\right)$ was dissolved and added to ACSF solution and recordings were done after 1 $\mathrm{min}$ of $1 \mathrm{ml} / \mathrm{min}$ perfusion of $\mathrm{NH}_{4} \mathrm{Cl}$-containing ACSF.

\section{Tris and HEPES experiments}

Tris and HEPES were added to a regular ACSF-based solution containing low $\mathrm{NaCl}$ concentration. The $\mathrm{pH}$ was adjusted to 7.5 with either sodium hydroxide $(\mathrm{NaOH})$ and osmolarity was maintained at $290 \mathrm{mOsm}$. In these experiments, final $\mathrm{NaCl}$ concentration was not decreased $<100$ mM.

\section{Cell culture and fluorescence imaging}

Hippocampal cultures were prepared from 2- to 3-d-old Sprague Dawley rat pups as described in detail previously (Kavalali et al., 1999). After $15-25 \mathrm{~d}$, cultures were placed in a recording chamber and superfused with saline containing the following (in $\mathrm{mM}$ ): $150 \mathrm{NaCl}, 4 \mathrm{KCl}, 4 \mathrm{MgCl}_{2}$, 10 Glucose, 10 HEPES, and $4 \mathrm{CaCl}_{2}, \mathrm{pH} 7.4, \sim 310 \mathrm{mOsm}$ at $21^{\circ} \mathrm{C}$. Electrophysiological recordings and the various treatments followed the same protocols as in slice experiments. Kynurenic acid (KYN; $1 \mathrm{~mm}$ ) was added directly to Tyrode's solution. Hypertonic solution was prepared by addition of $500 \mathrm{~mm}$ sucrose to the Tyrode's solution.

For FM dye fluorescence imaging experiments, synaptic boutons were loaded with FM 2-10 (400 $\mu \mathrm{M}$; Invitrogen, Eugene, OR) during $90 \mathrm{~s}$ incubation in hyperkalemic solution $47 \mathrm{mM} \mathrm{K}{ }^{+} / 2 \mathrm{mM} \mathrm{Ca}^{2+}$. This protocol gives maximal labeling as judged by comparison to loading with 1200 action potentials applied at $10 \mathrm{~Hz}$, which labels $90 \%$ of this total pool. Modified Tyrode solution used in all experiments contained the following (in mM): $150 \mathrm{NaCl}, 4 \mathrm{KCl}, 2 \mathrm{MgCl}_{2}, 10$ Glucose, $10 \mathrm{HEPES}$, and $2 \mathrm{CaCl}_{2}, \mathrm{pH} 7.4, \sim 310 \mathrm{mOsm}$. 


\section{Excitatory Synapses}
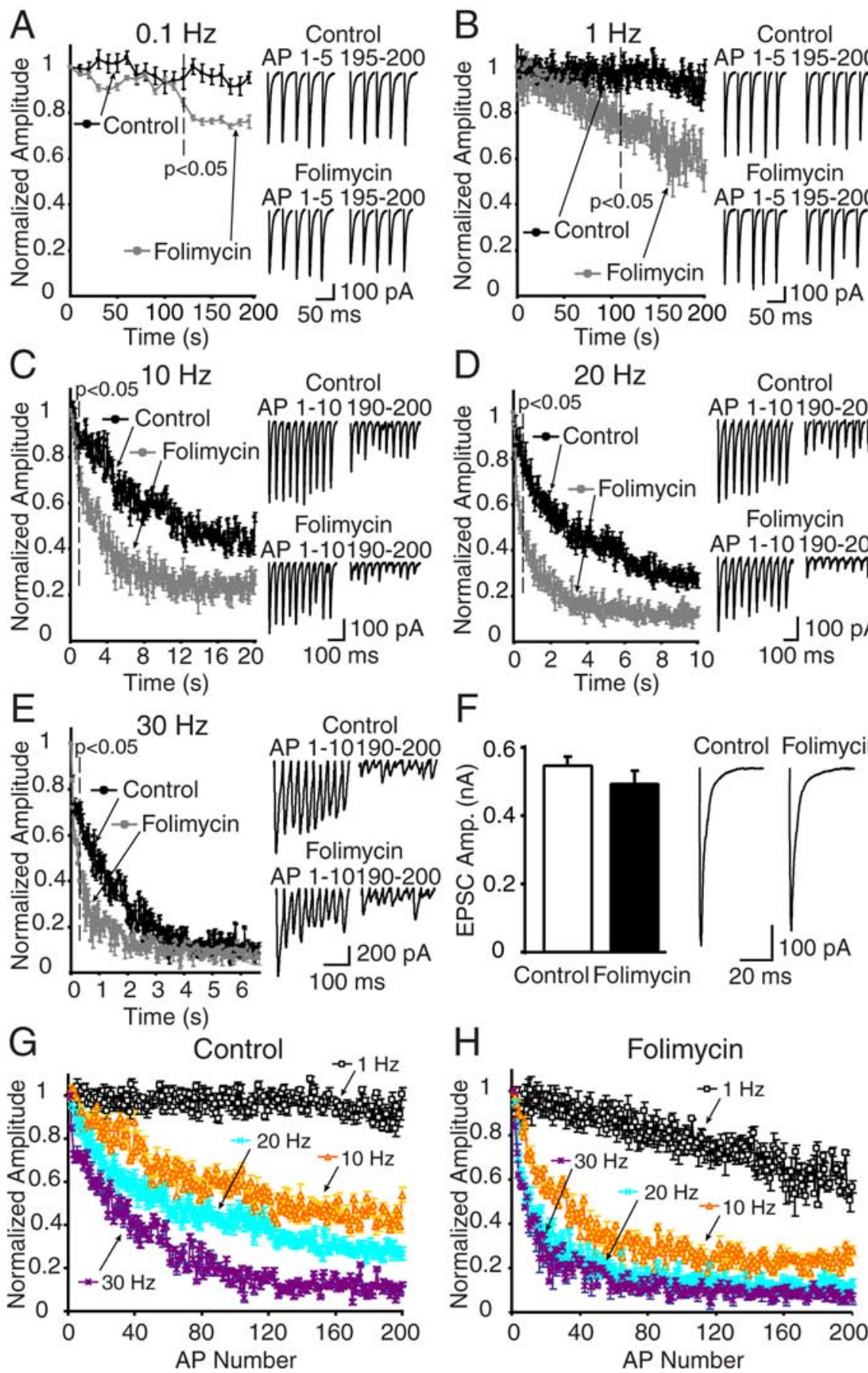

Figure 1. Folimycin treatment induces frequency-dependent depression of synaptic responses at excitatory synapses in the CA1 region of hippocampal slices. $\boldsymbol{A}-\boldsymbol{E}$, Blockade of vesicle refilling evaluated by synaptic depression at $0.1(\boldsymbol{A}), 1(\boldsymbol{B}), 10(\boldsymbol{C}), 20$ $(\boldsymbol{D})$, and $30 \mathrm{~Hz}(\boldsymbol{E})$ electrical stimulation after $10 \mathrm{~min}$ of folimycin exposure. Folimycin treatment hastened synaptic depression at excitatory synapses in higher frequencies with an early onset. Insets show the first and last 5 AP-evoked EPSCs at 0.1 and $1 \mathrm{~Hz}$, and the first and last 10 responses for 10,20 , and $30 \mathrm{~Hz}$ of continuous stimulation from individual recordings (the top trace for each experimental protocol represents controls and the bottom trace folimycin-treated cells). Folimycin-treated slices respond to stimulation with a continuous decline in neurotransmitter release with a faster rate of depression than that recorded in controls ( $p<0.05 ; n=5-7$ cells for each experimental protocol and group). The decline was more prominent at higher frequencies in the folimycin-treated group. $\boldsymbol{F}$, Bar graphs and representative traces of the average amplitude of the first evoked responses to the stimulation trains. There was a small but statistically insignificant decrease in the amplitudes of the first evoked responses recorded from folimycin-treated cells. Data shown are mean \pm SEM. $\boldsymbol{G}, \boldsymbol{H}$, Synaptic depression shows a dramatic frequency dependent increase at frequencies $>1 \mathrm{~Hz}$, regardless of the number of action potentials applied. Plots show depression induced by $1,10,20$, and $30 \mathrm{~Hz}$ stimulation frequencies applied for 200 pulses at pharmacologically isolated excitatory synapses (G) and after folimycin treatment $(\boldsymbol{H})$. Plots were prepared from the data presented in $\boldsymbol{A}-\boldsymbol{E}$. At 0.1 and $1 \mathrm{~Hz}$, fast time constants of synaptic depression from vehicle-treated slices were $303.1 \pm 22.9$ and $180.1 \pm 48.4 \mathrm{~s}$, respectively. At these frequencies, the time
Synaptophluorin experiments

Hippocampal cultures were prepared from spH21 transgenic mice at postnatal day 1 or 2 . These mice express synaptophluorin predominantly at excitatory synapses as described previously ( $\mathrm{Li}$ et al., 2005). Cultures were used for experiments after $21 \mathrm{~d}$ in vitro because at this time point surface fluorescence starts to be detectable. Control solution contained the following (in mM): $98 \mathrm{NaCl}, 2.3 \mathrm{KCl}, 2 \mathrm{MgCl}_{2}, 10$ Glucose, 10 HEPES, pH 7.4. Osmolarity was adjusted to $\sim 310 \mathrm{mOsm}$ by adding sucrose. For the $100 \mathrm{~mm}$ Tris solution, $100 \mathrm{~mm}$ Tris was added to control solution and osmolarity of the $100 \mathrm{~mm}$ Tris solution was at $310 \mathrm{mOsm}$ without sucrose addition. In addition, $2 \mathrm{mM} \mathrm{Ca}^{2+}, 10$ $\mu \mathrm{M}$ CNQX, and $50 \mu \mathrm{M}$ AP- 5 were added before all experiments. For Tris $(15 \mathrm{~mm}), \mathrm{NH}_{4} \mathrm{Cl}$, folimycin, and HEPES experiments, drugs were added to Tyrode's solution. Mature spH cultures were placed in a chamber containing either control or $100 \mathrm{~mm}$ Tris solution. After obtaining baseline images every second for $20 \mathrm{~s}$, cultures were stimulated with field stimulation, washed with control solution for $10 \mathrm{~min}$, and stimulation was repeated after wash. Isolated boutons were selected for analysis and the fluorescence values of the same boutons were analyzed before and after wash. Images were acquired with a cooled CCD camera (CoolSnap HQ or I-Pentamax; Roper Scientific, Trenton, $\mathrm{NJ})$ during illumination $(100 \mathrm{~ms})$ at $480 \pm 20$ $\mathrm{nm}$ (505 dichroic long pass and $534 \pm 25$ bandpass) via an optical switch (Sutter Instruments) and analyzed using Metafluor Software (Universal Imaging, Auburn Hills, MI).

For experiments presented in Figure 3, dissociated cultures were infected with synaptophysin-pHluorin lentivirus at $8 \mathrm{~d}$ in vitro and experiments were performed starting at 13-14 d in vitro. The synaptophysinpHluorin construct contained two pHluorins and was a generous gift of Drs. Y. Zhu and C.F. Stevens (The Salk Institute, La Jolla, CA) (Zhu et al., 2004).

Statistical analyses

Statistical differences were established using a two-tailed Student's $t$ test or KolmogorovSmirnov test (see Fig. 4). All data are expressed as mean \pm SEM.

\section{Results}

Frequency-dependent augmentation of synaptic depression by the v-ATPase inhibitor folimycin

Naturally occurring macrolide antibiotics such as bafilomycin A1 and folimycin (also

constants from folimycin-treated slices were comparable $(276.8 \pm 27.5$ and $165.8 \pm 31.3$ s, respectively; $p>0.50$ for each frequency) with controls. At 10,20, and $30 \mathrm{~Hz}$, the time constants of synaptic depression were faster at folimycintreated excitatory synapses compared with controls (at 10,20, and $30 \mathrm{~Hz}$ stimulation, the time constants, respectively, were $2.1 \pm 0.3,1.7 \pm 0.1$, and $1.1 \pm 0.2$ s for controls, and $1.33 \pm$ $0.1,1.1 \pm 0.1$, and $0.7 \pm 0.1$ sfor folimycin-treated synapses; $p<0.05$ for all; $n=5-7$ cells). 
called concanamycin A) can reduce synaptic output by selectively decreasing the neurotransmitter refilling (Roseth et al., 1995; Fonnum et al., 1998). This effect is attributed to their blockade of $\mathrm{v}$-ATPase which acidifies the lumen of recently endocytosed vesicles and generates an electrical and $\mathrm{pH}$ gradient (Moriyama and Futai, 1990). The neurotransmitter refilling process is maintained by transporters coupled to this proton pump to create the necessary driving force (Drose and Altendorf, 1997). Thus, after inhibition of this vesicular proton pump, endocytosed vesicles cannot be reloaded with neurotransmitter and, therefore, when reused, these vesicles cannot evoke synaptic responses for a second time. In this way, postsynaptic recordings from synapses treated with proton pump inhibitors only exhibit responses originating from previously unused vesicles within the recycling pool. Although bafilomycin has recently been used in studies that investigate the synaptic vesicle endocytosis with optical $\mathrm{pH}$ sensitive probes (Sankaranarayanan and Ryan, 2001), we preferred folimycin because the affinity of folimycin $(\mathrm{Ki}=20 \mathrm{pM})$ for $\mathrm{v}$-ATPase is 25-fold higher than that of bafilomycin $(\mathrm{Ki}=500$ pM) (Drose and Altendorf, 1997). This property of folimycin allowed us to use lower concentrations of vehicle (DMSO), which has effects of its own at higher concentrations (Y. Sara and E. T. Kavalali, unpublished observation).

We found that folimycin treatment $(67 \mathrm{nM}$ for $10 \mathrm{~min}$ ) of hippocampal slices resulted in a use-dependent blockade of synaptic transmission compared with vehicle-treated controls. Electrical stimulation of folimycin-treated Schaffer collateral synapses at frequencies of 0.1 and $1 \mathrm{~Hz}$ invoked slow depression of excitatory responses, which became significant $\sim 100 \mathrm{~s}$ into the stimulation when compared with control slices (Fig. $1 A, B$ ). In contrast, in response to stimulation frequencies of 10,20 , and 30 $\mathrm{Hz}$, synapses treated with folimycin manifested more rapid depression compared with their vehicle-treated counterparts (Fig. $1 C-E)$. Surprisingly, under these conditions, the difference between folimycin-treated and vehicle-treated synapses emerged within $1 \mathrm{~s}$. At $10 \mathrm{~Hz}$ stimulation, the decrease in peak amplitudes of responses was significantly different within $900 \mathrm{~ms}(p<0.05)$ whereas at 20 and $30 \mathrm{~Hz}$ stimulation, there was a clear difference in the depression rate within the first $300 \mathrm{~ms}$. Interestingly, the difference in $30 \mathrm{~Hz}$ was small and not significant after $2.6 \mathrm{~s}$, consistent with a decrease in the contribution of recycled vesicles to neurotransmission at this frequency. At rest, treatment with folimycin had minimal effect on the amplitude of evoked transmission; for instance, after a 10 min treatment with folimycin we only detected a $10 \%$ decrease in the initial response amplitudes (Fig. $1 F$ ). This finding is also consistent with the relative stability of synaptic responses during folimycin application at lowfrequency stimulation (Fig. 1A,B) (Sara et al., 2005).

Next, we wanted to distinguish the use-dependence of synaptic depression from its frequency dependence by replotting the data with respect to the number of elicited action potentials rather than time (Fig. $1 G, H$ ). These plots revealed a striking difference between the use dependence of depression induced by 1 $\mathrm{Hz}$ stimulation versus 10,20 , and $30 \mathrm{~Hz}$ stimulations for excitatory synapses (Fig. $1 G, H$ ). Two hundred pulses applied at $1 \mathrm{~Hz}$ do not induce substantial synaptic depression under control as well as folimycin-treated conditions. In contrast, starting at $10 \mathrm{~Hz}$, the same number of action potentials induces marked depression, which is substantially hastened after folimycin treatment. Folimycin addition decreases the difference among the depression plots at frequencies $>10 \mathrm{~Hz}$. This analysis suggests that synaptic depression is not only use dependent but also frequency dependent, especially $>1 \mathrm{~Hz}$. This finding implies that the difference between the kinetics of depression between $1 \mathrm{~Hz}$ versus higher frequencies cannot be explained by differences in synaptic vesicle recycling but may originate from a slow replenishment process because folimycin treatment does not bring the extent of depression detected at $1 \mathrm{~Hz}$ to the level seen at $10 \mathrm{~Hz}$ per action potential basis. Alternatively, it is also possible that synaptic depression at $10 \mathrm{~Hz}$ and higher frequencies is not attributable to vesicle depletion, but induced by a process that limits the vesicles' availability for fusion, and this process is not rate limiting at $1 \mathrm{~Hz}$. For instance, inactivation of voltage-gated calcium channels seen at moderate frequencies may curb vesicle release under these conditions ( $\mathrm{Xu}$ and $\mathrm{Wu}, 2005)$.

\section{The impact of folimycin treatment on inhibitory transmission in the CA1 region}

In the next set of experiments, we focused on inhibitory transmission onto CA1 pyramidal cells by pharmacologically isolating GABAergic responses. When we stimulated GABAergic transmission, the responses did not show further depression when compared with vehicle-treated controls for the first $120 \mathrm{~s}$ at 0.1 $\mathrm{Hz}$ and first $117 \mathrm{~s}$ at $1 \mathrm{~Hz}$ (Fig. $2 A, B$ ). Increasing the stimulation frequency from 10 up to $30 \mathrm{~Hz}$ revealed a rapid depression, which followed a similar time course as excitatory synaptic transmission evoked at the same frequencies (Fig. 2C-E). The folimycininduced depression of inhibitory responses showed a rapidly emerging difference between control and experimental groups within the first $1 \mathrm{~s}$ period in parallel to the changes we detected in excitatory transmission (difference between control and folimycin groups during GABAergic transmission: $0.8 \mathrm{~s}$ at $10 \mathrm{~Hz} ; 0.2 \mathrm{~s}$ at $20 \mathrm{~Hz} ; 0.3 \mathrm{~s}$ at $30 \mathrm{~Hz} ; p<0.05$ for each condition). Incidentally, in contrast to excitatory synapses, the effect of folimycin on depression induced by $30 \mathrm{~Hz}$ was significant throughout the stimulation period. Folimycin treatment alone, in the absence of stimulation, decreased synaptic responses by only $16 \%$ over 10 min (Fig. 2 F). When we replotted these data with respect to the number of elicited action potentials rather than time, we observed a striking difference between the use dependence of depression induced by $1 \mathrm{~Hz}$ stimulation versus 10,20 , and $30 \mathrm{~Hz}$ stimulations, similar to what we detected at excitatory synapses (Fig. 2G,H). This analysis suggests that inhibitory synaptic depression, as excitatory synaptic depression, displays a steep frequency dependence at frequencies $>1 \mathrm{~Hz}$.

Together, these observations suggest that rapid reuse of synaptic vesicles normally slows the rate of depression seen in excitatory and inhibitory synapses onto CA1 pyramidal cells and once vesicle refilling is blocked, the synaptic depression rate is significantly hastened. It is also possible that folimycin impairs fusion or vesicle recruitment, thus accelerating synaptic depression without impairing the contribution of reused vesicles. However, the latter premise is inconsistent with the time independence of the folimycin effect. Even after long treatments with folimycin, in the absence of stimulation or in the presence of low-frequency stimulation, we detected only a slow decrease in synaptic response amplitudes. Furthermore, in dissociated hippocampal cultures, folimycin treatment did not have a significant effect on the rate of vesicle mobilization detected by the release of rapidly departitioning FM dye FM2-10 in response to 10, 20, or $30 \mathrm{~Hz}$ stimulations. For instance, at a frequency of $20 \mathrm{~Hz}$, the time constant of FM2-10 loss from vehicle-treated cultures was $30.0 \pm$ $4.1 \mathrm{~s}(n=9)$, and from folimycin treated cultures was $35.8 \pm 6.5 \mathrm{~s}$ $(n=5 ; p>0.50)$. Other manipulations (see below) also did not alter the time constant of FM dye loss (salicylihalamide A, $35.8 \pm$ 


\section{Inhibitory Synapses}

A
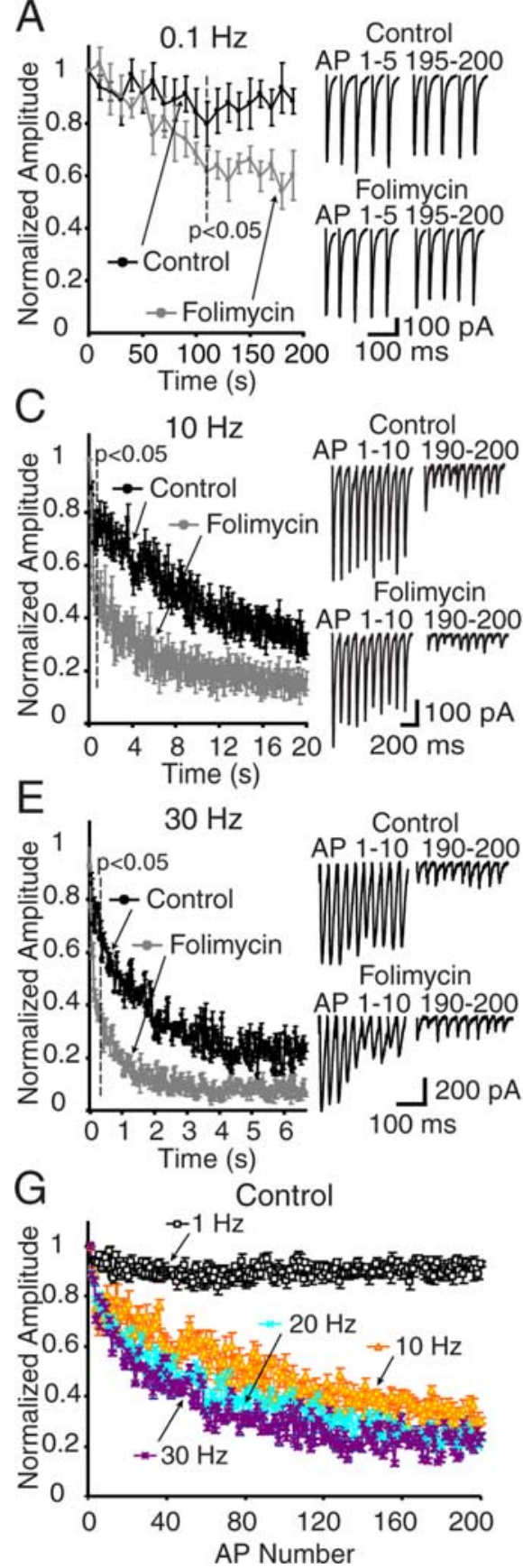
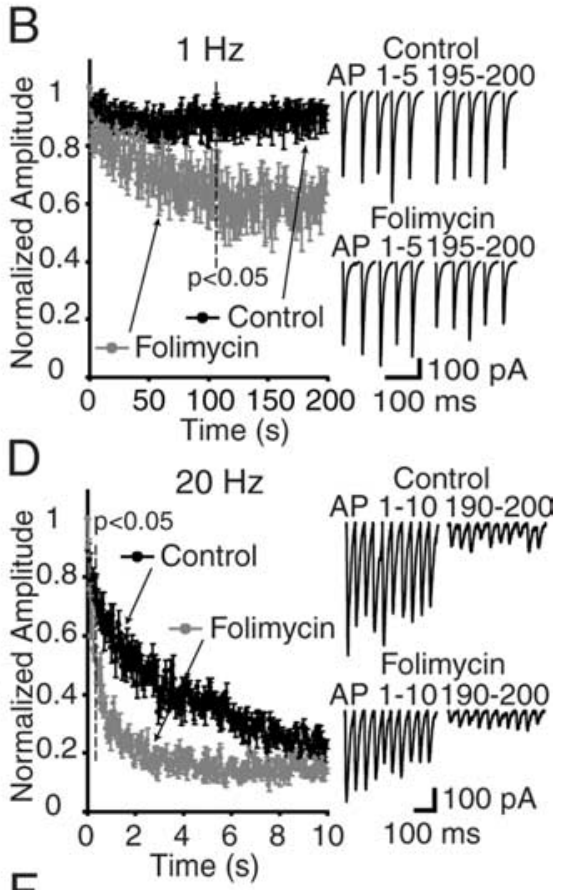

F
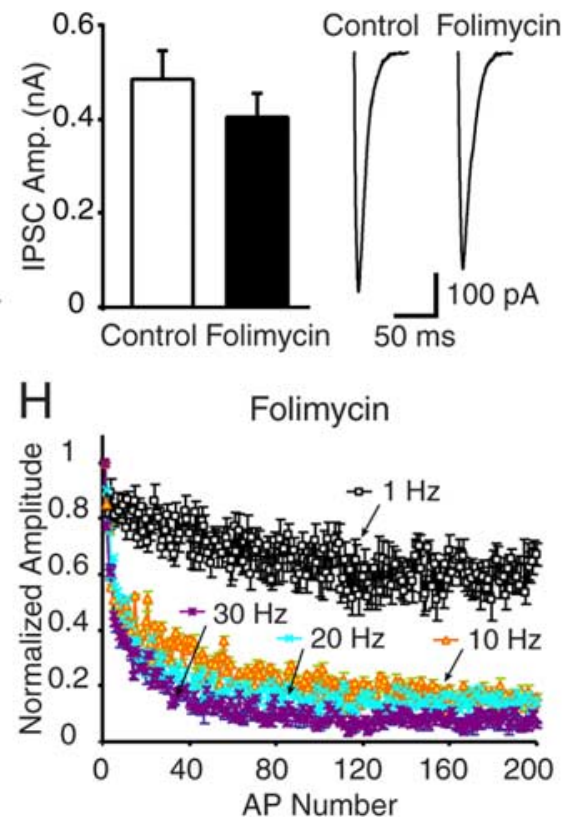

Figure 2. Inhibitory synapses in acute hippocampal slices show rapid depression after folimycin treatment. $\boldsymbol{A}-\boldsymbol{E}$, CA1 pyramidal neurons in hippocampal slices were treated with folimycin or vehicle controls for 10 min and subsequently synaptic depression was evaluated in the presence of CNQX (10 $\mu \mathrm{m})$ and AP-5 (50 $\mu \mathrm{m})$ to block excitatory currents, at $0.1(\boldsymbol{A}), 1(\boldsymbol{B}), 10(\boldsymbol{C}), 20(\boldsymbol{D})$, and $30 \mathrm{~Hz}(\boldsymbol{E})(n=5-8$ for each protocol). Similar to excitatory synapses, folimycin blocked the vesicular refilling in a frequencydependent manner. Trains of higher-frequency stimulation caused a more rapid decline of vesicles and faster depression rate in folimycin-exposed synapses when compared with controls $(p<0.05)$. Insets are sample traces from the first and last 5 APevoked IPSCs at $0.1(\boldsymbol{A})$ and $1 \mathrm{~Hz}(\boldsymbol{B})$ and from the first and last 10 evoked IPSC at $10(\boldsymbol{C}), 20(\boldsymbol{D})$, and $30 \mathrm{~Hz}(\boldsymbol{E})$ electrical stimulation. $\boldsymbol{F}$, Sample traces of initial evoked IPSCs recorded from control and folimycin-treated cells. After folimycin treatment, the first evoked response in inhibitory synapses was slightly reduced, although this reduction did not reach to statistical significance. Data shown are mean \pm SEM. G, $\boldsymbol{H}$, Alteration in synaptic depression $>1 \mathrm{~Hz}$ is regardless of the number of action potentials applied at folimycin treated $(\boldsymbol{H})$ and untreated $(\boldsymbol{G})$ inhibitory synapses. Plots were prepared from the data presented in $\boldsymbol{A}-\boldsymbol{E}$. At 0.1 and $1 \mathrm{~Hz}$, time constants of synaptic depression were $576.0 \pm 15.9$ and $222.0 \pm 24.6 \mathrm{~s}$, respectively. The time constants at 0.1 and $1 \mathrm{~Hz}$ were similar at folimycin-treated synapses ( $503.8 \pm 19.4$ and $212.0 \pm 54.1$ s respectively; $p>0.50 ; n=5-7$ cells). At higher frequencies, time constants from folimycin-treated synapses were lower when compared with controls (at 10, 20, and $30 \mathrm{~Hz}$ : $2.86 \pm 0.8,1.12 \pm 0.1$, and $0.70 \pm 0.1$ s respectively for controls, and $0.90 \pm 0.1,0.70 \pm 0.1$, and $0.30 \pm 0.1 \mathrm{~s}$ for folimycintreated; $p<0.05$ for each frequency; $n=5-8$ cells for each group).

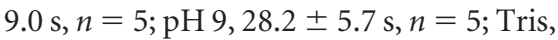
$33.4 \pm 9.2 \mathrm{~s}, n=6 ; p>0.50$ for all).

We also tested whether folimycin application had an effect on vesicle fusion by monitoring the extent of the paired-pulse ratio (from $33 \mathrm{~ms}$ up to $1 \mathrm{~s}$ intervals). There was no significant difference between folimycin and vehicle-treated controls, suggesting that folimycin application did not alter neurotransmitter release probability at stimulation onset (supplemental Fig. 1, available at www.jneurosci. org as supplemental material).

\section{The effect of folimycin on synaptic depression induced in dissociated hippocampal cultures}

Another possible explanation for these findings is that folimycin may impair voltage-gated $\mathrm{Ca}^{2+}$ and/or $\mathrm{Na}^{+}$channel function, which may induce rapid channel inactivation, thus leading to rapid synaptic depression. If this were the case, we would expect this effect to disappear when we trigger neurotransmitter release in the absence of synaptic excitation and $\mathrm{Ca}^{2+}$ influx. To test this possibility, we invoked neurotransmitter release in dissociated hippocampal cultures using hypertonic sucrose stimulation $(+500 \mathrm{mOsm})$, which is a $\mathrm{Ca}^{2+}$-independent way to trigger fusion of vesicles resident within the readily releasable pool (RRP). In hippocampal cultures, hypertonic sucrose-induced release typically shows a rapid peak and a sustained plateau phase. However, these two kinetic components of release are not readily discernable in hippocampal slices (data not shown). The rapid peak component of release is generally attributed to mobilization of the RRP whereas the sustained component is mainly attributed to replenishment of RRP vesicles from a reserve pool (Rosenmund and Stevens, 1996; Moulder and Mennerick, 2005) or by rapid vesicle recycling (Sara et al., 2002). In agreement with these previous findings, folimycin treatment substantially inhibited the sustained component of release with minimal effect on the kinetics and amplitude of the peak component $(p<0.05$ after $24 \mathrm{~s})$ (Fig. 3A). Therefore, the effect of folimycin is not dependent on $\mathrm{Ca}^{2+}$ influx or neuronal excitability.

In dissociated hippocampal cultures, in parallel with the results presented above, folimycin treatment augmented synaptic depression rate at $10 \mathrm{~Hz}$ stimulation, but only slowly decreased transmission at low frequencies. At 0.1 or $1 \mathrm{~Hz}$ stimulation, folimycin-induced increase in synaptic depression rate reached to statistical significance after $100 \mathrm{~s}$ (Fig. $3 \mathrm{~B}, \mathrm{C}$ ). In contrast, 
at $10 \mathrm{~Hz}$ stimulation, the onset of significance was at $1.8 \mathrm{~s}$ (Fig. 3D) $(p<0.05)$. This finding contradicts our previous results in dissociated hippocampal cultures, which estimated a minimal contribution of synaptic vesicle reuse to neurotransmission during $10 \mathrm{~Hz}$ stimulation (Sara et al., 2002; Virmani et al., 2006). These previous studies have compared FM dye release kinetics and postsynaptic electrical recordings to measure the time course of synaptic vesicle recycling (Betz and Bewick, 1992, 1993; Sara et al., 2002). To estimate the time course of synaptic vesicle recycling from the kinetic comparison of dye release and postsynaptic electrical signals, we have to assume a linear relationship between the electrical and optical measures. To test this assumption, we used the rapidly dissociating AMPA receptor antagonist KYN, which competes with the endogenous levels of glutamate (Diamond and Jahr, 1997) (for a detailed discussion, see supplemental Fig. 2,available at www.jneurosci.org as supplemental material). This analysis suggested that postsynaptic recordings obtained with field stimulation in hippocampal cultures are not linear detectors of presynaptic neurotransmitter release during sustained high-frequency stimulation.

\section{Imaging the effect of folimycin treatment on synaptophysin-pHluorin turnover in hippocampal cultures}

The rapid impact of folimycin on synaptic depression suggests that during repetitive stimulation synaptic vesicles can be endocytosed and reacidified within hundreds of milliseconds after exocytosis. To test this premise, in the next set of experiments, we imaged the effect of folimycin at the level of individual hippocampal synapses. For this purpose, we infected hippocampal cultures with lentivirus expressing the four transmembrane domain synaptic vesicle protein synaptophysin tagged with superecliptic pHluorin (synaptophysinpHluorin). Superecliptic pHluorin is a GFP-based $\mathrm{pH}$ sensor that is normally quenched at pH 5.5 within the vesicle lumen, but fluoresces once vesicles fuse and the fluorophore is exposed to extracellular pH (7.4) (Miesenbock et al., 1998). This construct manifests minimal surface fluorescence compared with the synaptophluorin, which is a fusion construct of synaptobrevin (Zhu et al., 2004; Granseth et al., 2006).

In response to field stimulation at $20 \mathrm{~Hz}$ for $2 \mathrm{~s}$, synaptophysin-pHluorin fluorescence showed a swift increase and a gradual slow return to baseline in agreement with previous observations (Granseth et al., 2006), presumably because of slow compensatory endocytosis as well as prominent asynchronous release after burst stimulation (Maximov and Sudhof, 2005). Five
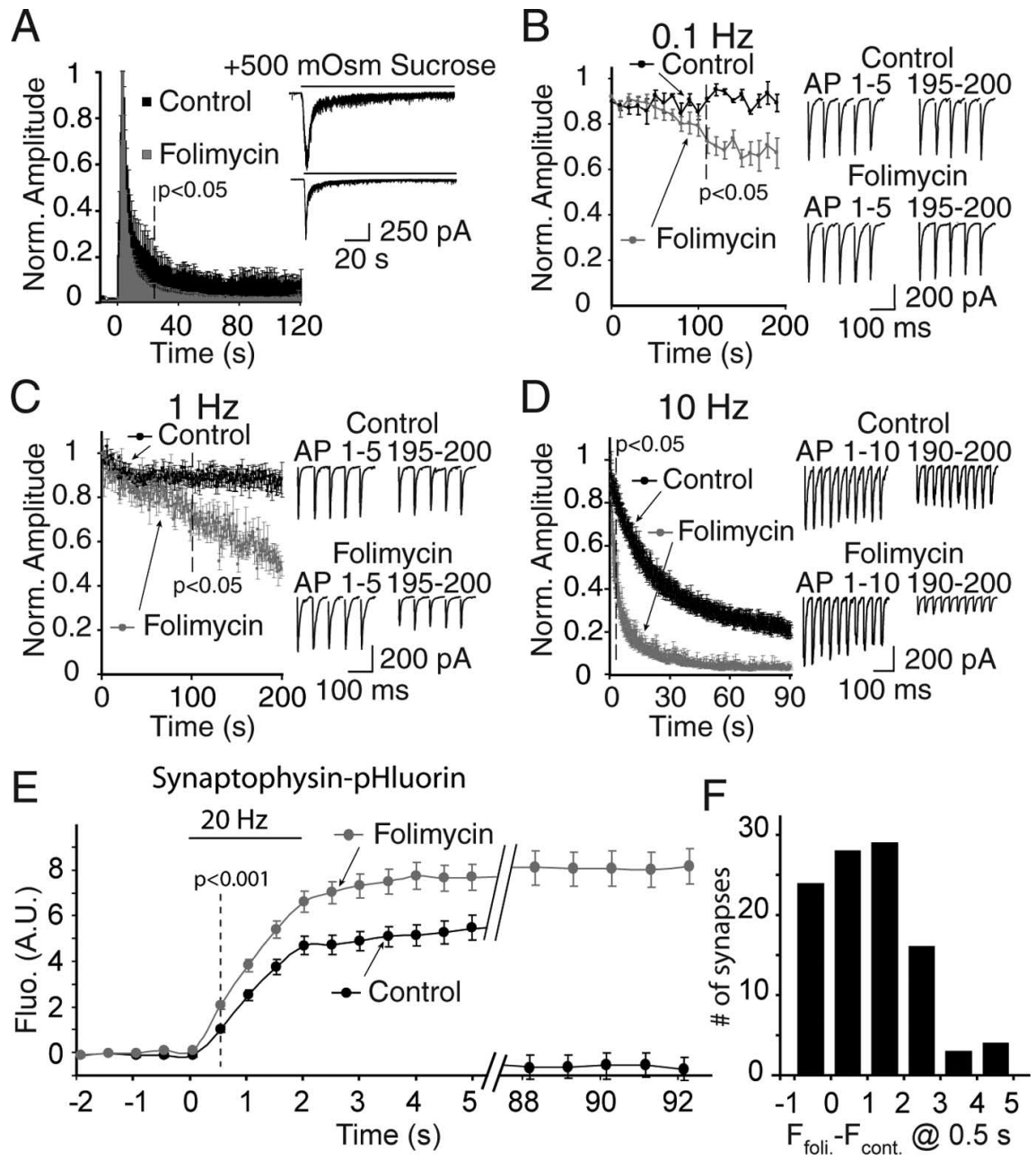

Figure 3. Effect of folimycin on sustained phase of hypertonic sucrose-evoked release and synaptic depression rate at hippocampal cultures. $\boldsymbol{A}$, Folimycin blocks the sustained phase of release induced by hypertonic sucrose stimulation. Hippocampal cultures were exposed to a $500 \mathrm{m0sm}$ sucrose solution. Whole-cell patch-clamp recordings show a biphasic response with an initial peak neurotransmitter release followed by a steady-state plateau release phase. Average integrated responses normalized to their respective peak responses show a loss of steady-state phase of release in folimycin-treated cells ( $n=4$ cells) compared with controls ( $n=5$ cells), which reached to statistical significance within $25 \mathrm{~s}$ ( $p<0.05)$. Representative traces from control and folimycin groups are shown at inset. $\boldsymbol{B}-\boldsymbol{D}$, Blockade of vesicle refilling by folimycin evaluated by recording synaptic depression at $0.1(\boldsymbol{B}), 1(\boldsymbol{C})$, and $10 \mathrm{~Hz}(\boldsymbol{D})$ electrical stimulation after $10 \mathrm{~min}$ of folimycin exposure in hippocampal cell cultures. Similar to synapses from the CA1 region of hippocampal slices, folimycin treatment hastened synaptic depression in higher frequencies with an earlier onset. Insets show the first and last 5 AP-evoked EPSCs at $0.1 \mathrm{and} 1 \mathrm{~Hz}$, and the first and last 10 responses for $10 \mathrm{~Hz}$ of continuous stimulation from individual recordings (the top trace for each experimental protocol represents controls and the bottom trace folimycin-treated coverslips). Folimycin-treated cultured neurons respond to stimulation with a continuous decline in neurotransmitter release with a faster rate of depression than the synapses sampled under control conditions $(p<0.05 ; n=$ 4-7 cells for each experimental protocol and group). The decline was more prominent at higher frequencies in the folimycintreated group. $\boldsymbol{E}$, In response to field stimulation at $20 \mathrm{~Hz}$ for $2 \mathrm{~s}$, synaptophysin-pHluorin fluorescence showed a swift increase and a gradual slow return to baseline. Five minutes after an initial control experiment, we perfused the cultures with $67 \mathrm{~nm}$ folimycin and applied the same stimulation protocol to monitor the fluorescence change in the same set of synaptic boutons. After folimycin exposure, synaptophysin-pHluorin fluorescence showed a larger increase detectable within the first $500 \mathrm{~ms}$ ( $n=4$ experiments; 101 boutons; $\left.{ }^{*} p<0.001\right)$. $\boldsymbol{F}$, The distribution of the differences in fluorescence within the first 500 ms detected before and after folimycin treatment was skewed toward positive values. foli, Folimycin; cont, control. Data shown are mean \pm SEM. 
A
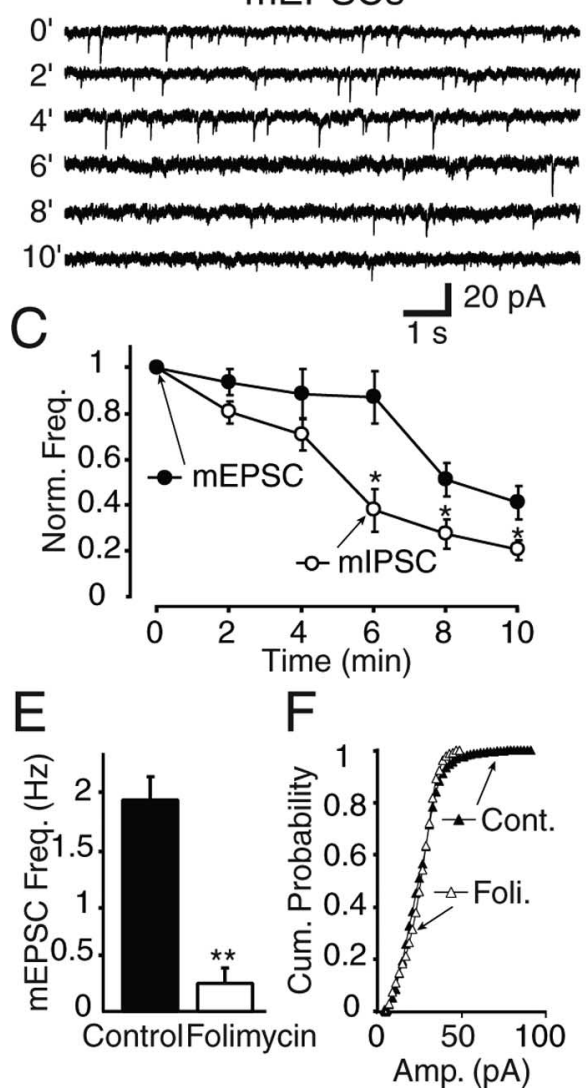

B
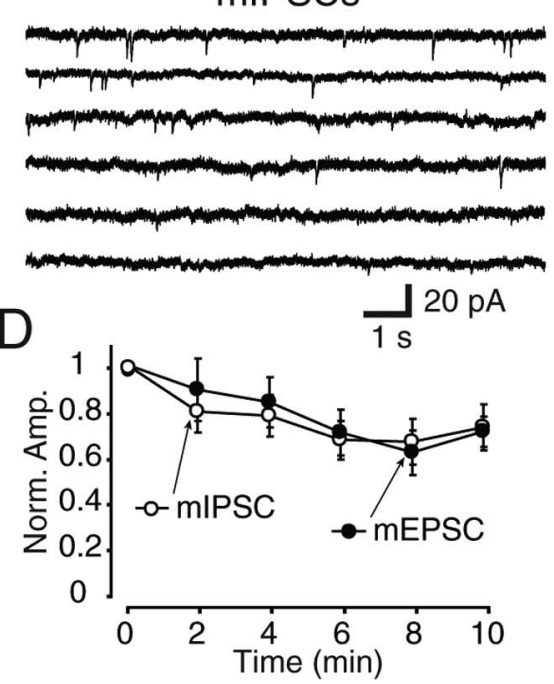

$G$

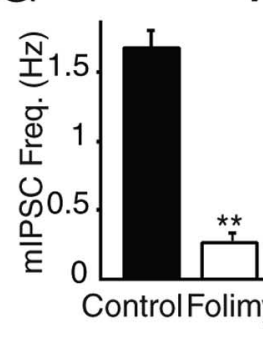

$\mathrm{H}$

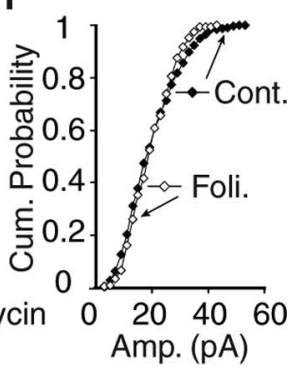

Figure 4. Effects of folimycin treatment on miniature spontaneous events at excitatory and inhibitory synapses, recorded from CA1 pyramidal neurons. $\boldsymbol{A}, \boldsymbol{B}$, Sample traces of miniature EPSCS $(\boldsymbol{A})$ and IPSCS $(\boldsymbol{B})$, which were recorded during folimycin exposure

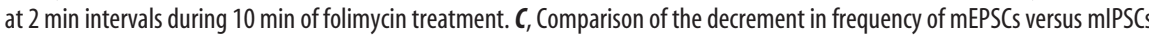
during $10 \mathrm{~min}$ of folimycin perfusion. The frequency of mIPSCs reduced faster than that of mEPSCs after 6 min of folimycin treatment $\left({ }^{*} p<0.05 ; n=8\right.$ for each group). $\boldsymbol{D}$, The decrease in the amplitude of $\mathrm{mEPSC}$ and mIPSCs were comparable during the onset of folimycin treatment. $\boldsymbol{E}, \boldsymbol{G}$, After $10 \mathrm{~min}$ of folimycin treatment, the frequencies of both glutamate- $(\boldsymbol{E})$ and $\mathrm{GABA}$ mediated $(\boldsymbol{G})$ miniature events were significantly lower (by $84 \pm 1 \%$ and $79 \pm 2 \%$, respectively; ${ }^{* *} p<0.001 ; n=8$ for each group). $\boldsymbol{F}, \boldsymbol{H}$, Cumulative probability plots of miniature events recorded from excitatory $(\boldsymbol{F})$ and inhibitory $(\boldsymbol{H})$ synapses at control slices and after 10 min of folimycin perfusion. Both mEPSCs $(\boldsymbol{F})$ and $\mathrm{mIPSCs}(\boldsymbol{H})$ showed a nonsignificant decrease in amplitude after 10 min of folimycin application ( $n=8$ neurons for each group; Kolmogorov-Smirnov test, $p>0.05$ for both plots). foli, Folimycin; cont, control. Data shown are mean \pm SEM.

The rapid increase in fluorescence seen after folimycin application is in agreement with previous findings using a similar manipulation (Fernandez-Alfonso and Ryan, 2004; Li et al., 2005). However, using paired recordings from synaptically coupled hippocampal neurons, Li et al. (2005) demonstrated an increase in electrophysiological responses after bafilomycin treatment, which could account for the increase in fluorescence signal. In contrast, in our study we used more robust field stimulation for electrophysiological experiments, the same type of stimulation used by us and Li et al. (2005) for fluorescence imaging, and did not detect an increase in electrical responses after folimycin treatment. Therefore, we propose that synaptic vesicles can be rapidly endocytosed and reacidified within $500 \mathrm{~ms}$ or less during repetitive stimulation, in agreement with our electrophysiological observations. This proposal contradicts previous findings in hippocampal cultures that synaptic vesicle reacidification proceeds through a relatively slow time course $(\sim 5 \mathrm{~s})$ (Atluri and Ryan, 2006; Granseth et al., 2006). These earlier measurements have specifically investigated synaptic vesicle reacidification during delayed endocytosis after stimulation and, therefore, they may have overlooked a fast component of vesicle reacidification.

The circumstances that cause at least some vesicles lose their protein complement during delayed endocytosis (FernandezAlfonso et al., 2006; Wienisch and Klingauf, 2006) may also lead to the disruption of the multi-subunit vacuolar ATPase complex, which is required for vesicle reacidification. The vesicles that are endocytosed with a delay after stimulation may end up being slowly reacidified whereas in vesicles with an intact ATPase complex, reacidification may proceed extremely rapidly. To address this issue conclusively and investigate synaptic vesicle reacidification process in further detail, we clearly need high-resolution rapid measurements performed during stimulation.

\section{The differential effect of folimycin on excitatory and inhibitory} spontaneous neurotransmission

To examine the impact of blocking neurotransmitter refilling on spontaneous neurotransmission onto CA1 pyramidal neurons, we monitored miniature EPSCs (mEPSCs) during folimycin treatment and compared their properties to miniature IPSCs (mIPSCs) (Fig. 4). During a 10min-long recording period, folimycin caused a gradual decrease in the frequency of mEPSCs as well as mIPSCs (Fig. $4 C, E, G)$ without a significant decrease in their amplitudes (Fig. 4D, F,H). This finding is consistent with our previous observations in dissociated hippocampal cultures that the loss of spontaneous events proceeds through a nearly "all-ornothing" process as spontaneously recycling vesicles undergo recycling. Because we used a detection threshold of $5 \mathrm{pA}$, spontaneous events that fall below this amplitude would not be registered. Therefore, folimycin treatment probably substantially reduces neurotransmitter refilling but does not abolish it completely. We also found that despite their lower baseline spontaneous release frequency, inhibitory synapses showed a faster onset of folimycininduced depression in release frequency and, thus, spontaneous vesicle reuse compared with excitatory synapses (Fig. 4C). These findings support the relative isolation of spontaneous and activity-dependent vesicle pools from one another in central synapses. In addition, the relative stability of mEPSC and mIPSC amplitudes during these recordings indicates that the density and number of postsynaptic receptors were not altered during folimycin treatment.

\section{Salicylihalamide A mimics the effect of folimycin}

In the next set of experiments, we used another high affinity $\mathrm{v}$-ATPase inhibitor, salicylihalamide A, to test the specificity of the folimycin effect (Xie et al., 2004). Treatment of hippocampal slices with salicylihalamide A (10 nM) resulted in a similar frequency-dependent augmentation of synaptic depression (Fig. $5 A, B)$. When we stimulated excitatory transmission at a frequency of $1 \mathrm{~Hz}$, response amplitudes in salicylihalamide 
A-treated slices showed a significant reduction only after $100 \mathrm{~s}$, compared with vehicle-treated controls (Fig. 5A). In contrast, when stimulated at $20 \mathrm{~Hz}$, synaptic responses in the presence of salicylihalamide A depressed rapidly within $200 \mathrm{~ms}$ of stimulation, mimicking the effect of folimycin under the same conditions (Fig. $5 B)$.

\section{Vesicle alkalinization after endocytosis} occludes the effect of folimycin

To test whether the effect of folimycin is attributable to its alkalinization of the synaptic vesicle interior after endocytosis, we performed experiments in the presence of $5 \mathrm{mM} \mathrm{NH}_{4} \mathrm{Cl}$ (Fig. 5C-E). In parallel with our observations with folimycin and salicylihalamide $\mathrm{A}$, we detected rapid augmentation of synaptic depression rate at 20 $\mathrm{Hz}$ stimulation in $\mathrm{NH}_{4} \mathrm{Cl}$-exposed excitatory synapses, whereas depression rate was only slowly increased at a stimulation frequency of $1 \mathrm{~Hz}$ (98th pulse, $98 \mathrm{~s}$ at $1 \mathrm{~Hz}$; 4th pulse, $0.25 \mathrm{~s}$ at $20 \mathrm{~Hz}$ ) (Fig. $5 C, D$ ). In addition, we did not observe an additional increase in the synaptic depression rate by perfusion of slices with both $\mathrm{NH}_{4} \mathrm{Cl}$ and folimycin, suggesting that the effect of folimycin is occluded in this condition (Fig. $5 E)$.

To further investigate the effect of alkalinization and inhibition of vesicular refilling on synaptic depression, we invoked excitatory synaptic transmission at a frequency of 1 and $20 \mathrm{~Hz}$ by perfusing the slices with alkaline ( $\mathrm{pH}$ 9) ACSF. Rapid application of alkaline ACSF did not significantly impair synaptic transmission at a frequency of $1 \mathrm{~Hz}$ (supplemental Fig. 3A, available at www.jneurosci.org as supplemental material). However, it significantly hastened synaptic depression at a frequency of $20 \mathrm{~Hz}$ (supplemental Fig. $3 B$, available at www.jneurosci.org as supplemental material). Furthermore, $20 \mathrm{~Hz}$ stimulation of synaptic transmission after the addition of folimycin to the alkaline perfusion solution did not result in an additional increase in depression, indicating that the alkaline medium occluded the effect of folimycin (supplemental Fig. 3C, available at www.jneurosci.org as supplemental material). Therefore, the increase in the rate of synaptic depression seen after folimycin treatment is attributed to its alkalinization of synaptic vesicle lumen after endocytosis.

We also explored whether we could repeat the same experiments using a solution at acidic $\mathrm{pH}$ ( $\mathrm{pH}$ 5.5), thus mimicking the vesicle lumen (Atluri and Ryan, 2006). However, application of an acidic ACSF solution rapidly and irreversibly decreased the membrane resistance of hippocampal pyramidal cells (supplemental Fig. 4A, $B$, available at www.jneurosci.org as supplemental material), indicating an irreversible increase in overall mem-
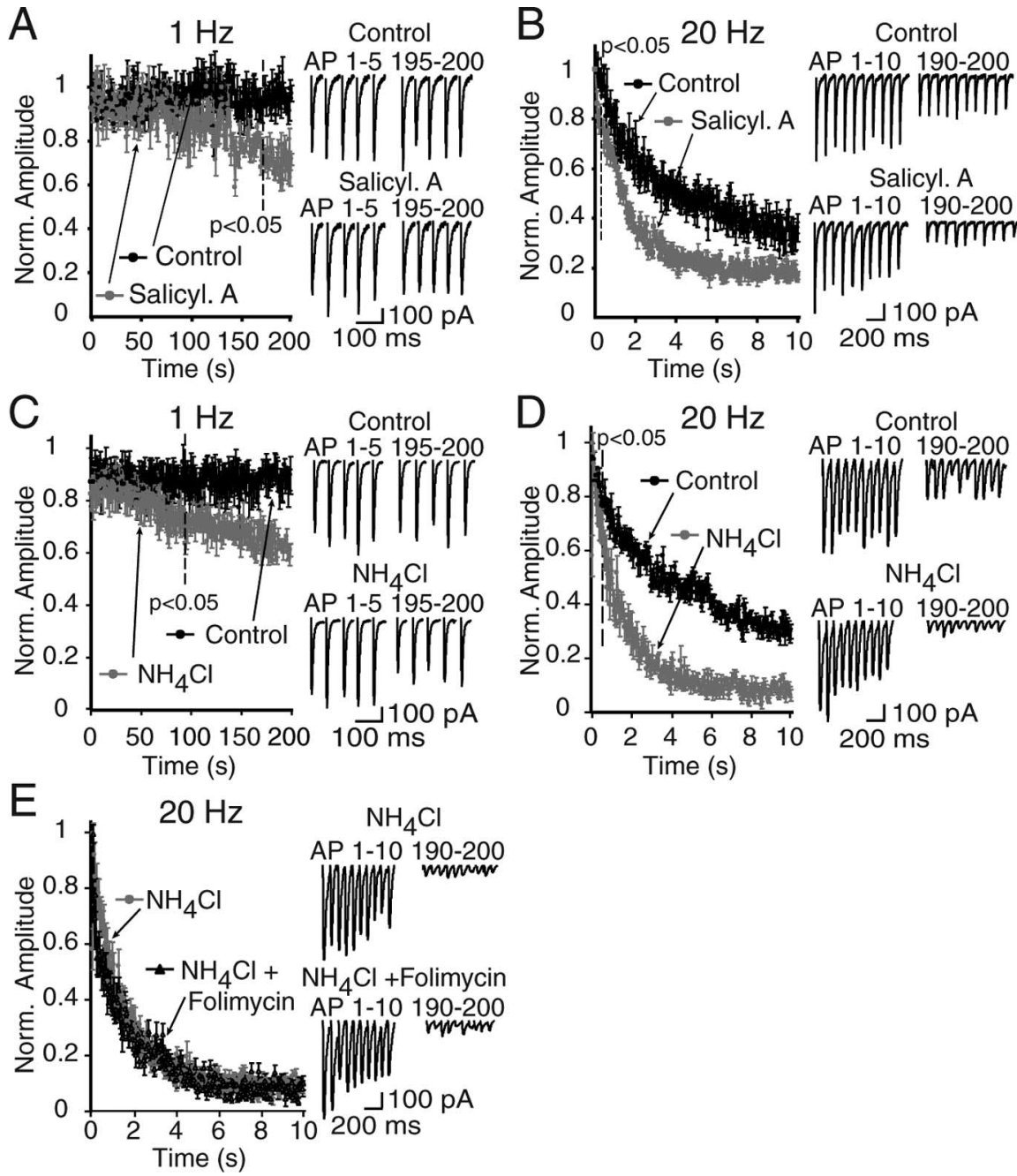

Figure 5. Effect of different manipulations that impair vesicular refilling on synaptic depression. $\boldsymbol{A}, \boldsymbol{B}$, The folimycin effect is mimicked by another v-ATPase inhibitor, salicylihalamide A. Effect of salicylihalamide A was investigated by recording EPSCS at $0.1 \mathrm{~Hz}(\boldsymbol{A})$ for $200 \mathrm{~s}$ and $20 \mathrm{~Hz}(\boldsymbol{B})$ for 10 s either in the presence of drug or vehicle at excitatory synapses of the CA1 region. Similar to the folimycin effect, salicylihalamide A pretreatment induced frequency-dependent synaptic depression ( $n=5$ for each group), which was faster than that of controls during high-frequency trains. Insets show the first and last pulses of EPSC trains in ontrol (top traces) and salicylihalamide A-treated (bottom traces) synapses. C, Plots showing the synaptic depression rate at $1 \mathrm{~Hz}$ $200 \mathrm{~s}$ electrical stimulation detected in neurons from control hippocampal slices and from $\mathrm{NH}_{4} \mathrm{Cl}$ perfused slices. Perfusion of hippocampal slices with $\mathrm{NH}_{4} \mathrm{Cl}(5 \mathrm{~mm})$ mimics the effect of folimycin on synaptic depression. The increase in synaptic depression rate reached to statistical significance after $98 \mathrm{~s}$ at the $\mathrm{NH}_{4} \mathrm{Cl}$-perfused group when compared with controls $(n=4 ; p<0.05)$. D 列 5 cells) compared with application of $\mathrm{NH}_{4} \mathrm{Cl}$ alone. Insets show the first and last 5 pulses at $1 \mathrm{~Hz}(\boldsymbol{C})$ and first and last 10 pulses at $20 \mathrm{~Hz}$ stimulation frequency $(\boldsymbol{D}, \boldsymbol{E})$ in each group. Plots demonstrating the synaptic depression rate at 1 and $20 \mathrm{~Hz}$ electrical stimulation at Schaffer collateral synapses are shown.

brane conductance and possible compromise of membrane integrity. In contrast, membrane resistance measurements were unaffected by application of the ACSF solution buffered at $\mathrm{pH} 9.0$ (supplemental Fig. 4C,D, available at www.jneurosci.org as supplemental material). When we increased the $\mathrm{pH}$ of the extracellular medium to 6.5 , a less-acidic condition, we did not detect a substantial change in the rate of synaptic depression induced by $20 \mathrm{~Hz}$ stimulation (supplemental Fig. $4 E$, available at www. jneurosci.org as supplemental material). In addition, application of folimycin at this acidic $\mathrm{pH}$ caused a swift increase in the rate of depression similar to its effect on control slices (supplemental Fig. $4 E$, gray symbols, available at www.jneurosci.org as supple- 
A
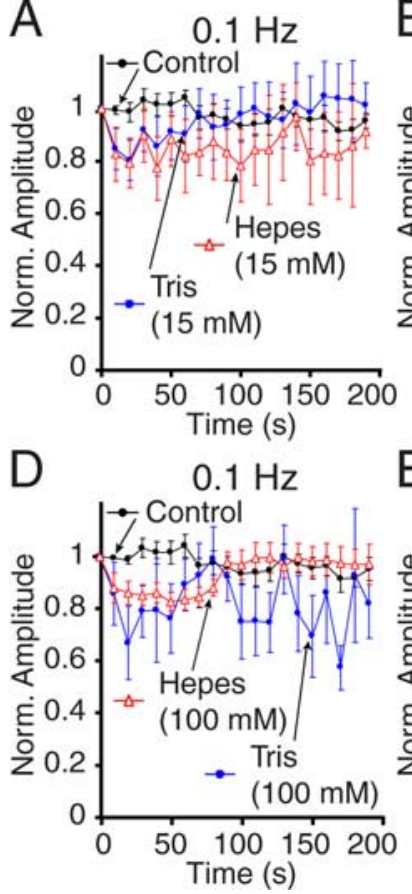

B

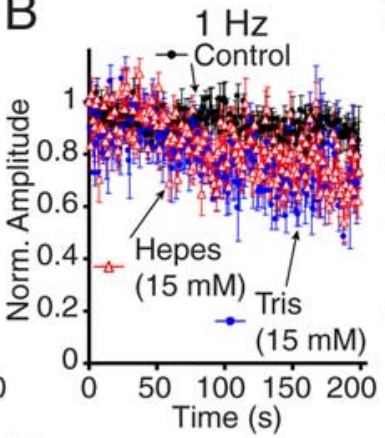

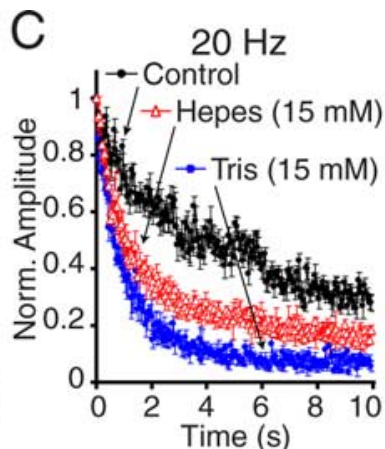

E

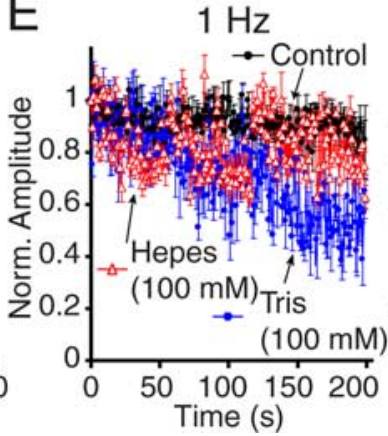

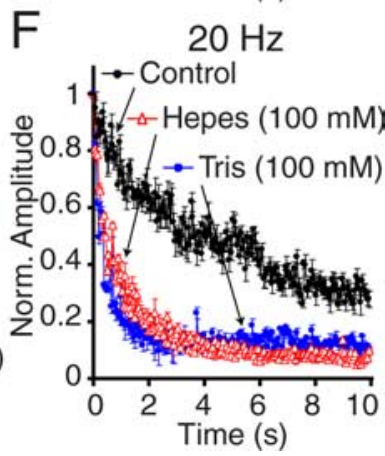

Figure 6. Effects of small pH buffers on synaptic depression. $\boldsymbol{A}-\boldsymbol{C}$, Plots showing the normalized EPSC amplitudes at $0.1(\boldsymbol{A}), 1$ $(\boldsymbol{B})$, and $20 \mathrm{~Hz}(\boldsymbol{C})$ trains in the presence of Tris $(15 \mathrm{~mm})$, HEPES (15 mM), or control perfusion solutions. Hippocampal slices were perfused with either Tris- or HEPES-buffered ACSF 5-10 min before the trains were recorded. $\boldsymbol{A}-\boldsymbol{F}$, The effect of Tris and HEPES buffers was evaluated at $15(\boldsymbol{A}-\boldsymbol{C})$ and $100 \mathrm{~mm}(\boldsymbol{D}-\boldsymbol{F})$ concentrations. At $15 \mathrm{~mm}$, HEPES and Tris did not cause significant depression during 0.1 and $1 \mathrm{~Hz}$ trains $(\boldsymbol{A}, \boldsymbol{B})$ compared with controls ( $n=6-8$ cells for each group). $\boldsymbol{C}$, During $20 \mathrm{~Hz}$ stimulation (for 200 pulses), we detected faster synaptic depression rates in slices treated with HEPES or Tris compared with controls (note that HEPES-treated slices showed slightly less depression) ( $n=6-8$ cells for each group, $p<0.05$ ). $\boldsymbol{D}-\boldsymbol{F}$, At a concentration of 100 $\mathrm{mm}$, Tris and HEPES were equally effective in increasing the rate of depression in a frequency-dependent manner. Note that during $20 \mathrm{~Hz}$ stimulation, the high concentration of $\mathrm{pH}$ buffers rapidly decreased transmission to a very low level (within $2 \mathrm{~s}$ ).

mental material). This result suggests that synaptic vesicle refilling can be perturbed even when synaptic vesicles are trapped at $\mathrm{pH}$ 6.5. This finding indicates that refilling of synaptic vesicles with neurotransmitters is very sensitive to small variations in synaptic vesicle acidification.

\section{Frequency-dependent augmentation of synaptic depression by small $\mathrm{pH}$ buffers}

The rapid reduction in synaptic responses seen after folimycin treatment was only weakly reversible, even after extended wash out and stimulation (data not shown) (Xie et al., 2004). This shortcoming prompted us to explore an alternative reversible means to impair neurotransmitter refilling and assess the kinetics of synaptic vesicle reuse. Reversible interference with neurotransmitter refilling can create an experimental setting akin to optical experiments using FM dyes, however, at an electrophysiological fast time resolution. For this purpose, we took advantage of the small $\mathrm{pH}$ buffers Tris and HEPES, which can be loaded into synaptic vesicles and impair vesicle acidification (Gandhi and Stevens, 2003). When we stimulated synaptic transmission in slices bathed with $15 \mathrm{~mm}$ Tris or $15 \mathrm{~mm}$ HEPES added to the $\mathrm{HCO}_{3}^{-}$-buffered extracellular ACSF solution, we detected a frequency-dependent augmentation of synaptic depression similar to the one we observed previously with folimycin (Fig. 6A$C)$. Fifteen micromolars Tris or HEPES did not result in significant synaptic depression at frequencies of 0.1 and $1 \mathrm{~Hz}$ (Fig. $6 A, B)$. However, both substantially facilitated the rate of depression at $20 \mathrm{~Hz}$ (Fig. 6C). At this concentration, Tris was slightly more effective than HEPES as judged by the relatively greater level of depression Tris caused at $20 \mathrm{~Hz}$ (Fig. 6C). The frequency dependence and the magnitude of the Tris and HEPES effect on synaptic depression was not significantly altered when we increased their concentrations to $100 \mathrm{~mm}$ to raise the buffering capacity (Fig. 6D-F). At this high concentration, HEPES and Tris were equally potent in causing rapid synaptic depression in response to $20 \mathrm{~Hz}$ stimulation (Fig. 6F). Interestingly, under these conditions, synaptic depression was nearly complete within $2 \mathrm{~s}$. This time frame was shown previously to be sufficient to label the RRP with FM1-43 at a frequency of 20 $\mathrm{Hz}$ (Murthy and Stevens, 1999), indicating that the depression we see in the absence of vesicle refilling is consistent with depletion of the RRP.

\section{Frequency-dependent recovery from Tris-induced depression}

Our results are consistent with the hypothesis that impairment of neurotransmitter refilling into synaptic vesicles after endocytosis abolishes their ability to invoke postsynaptic responses in subsequent rounds of fusion without affecting their ability to fuse. To test this premise further, we monitored the recovery of responses after depression induced by Tris (15 mM). In the absence of Tris, synaptic depression induced by $20 \mathrm{~Hz}$ stimulation for $10 \mathrm{~s}$ [200 action potential (APs)] recovers within $1 \mathrm{~s}$ when the stimulation frequency is switched to $1 \mathrm{~Hz}$ (Fig. 7A). In contrast, in the presence of Tris, synaptic responses do not show significant recovery for the next $90 \mathrm{~s}$ of stimulation (Fig. 7A). This is consistent with our inability to detect significant depression up to $100 \mathrm{~s}$ during $1 \mathrm{~Hz}$ stimulation in the presence of Tris (Fig. $7 \mathrm{~B}$ ).

After an extensive 10-min-long wash out of Tris-buffered ACSF, $1 \mathrm{~Hz}$ stimulation still failed to evoke full-scale synaptic responses (Fig. $7 B$ ). Interestingly, when we switched the stimulation frequency to $20 \mathrm{~Hz}$, we detected rapid response recovery, which showed typical depression during continuous stimulation. However, these responses could be rapidly recovered by switching stimulation frequency back to $1 \mathrm{~Hz}$, akin to our observations under control conditions (Fig. $7 B$ ). The result of this experiment indicates that recovery from Tris-induced depression is use dependent. Therefore, $1 \mathrm{~Hz}$ stimulation does not induce significant recovery, presumably because it cannot induce rapid synaptic vesicle reuse (which is needed to cause significant unloading of the Tris trapped in the vesicles). In contrast, the $20 \mathrm{~Hz}$ stimulation induced rapid vesicle reuse along with rapid synaptic depression, which resulted in transient recovery of synaptic responses from the Tris-induced depression.

In the next set of experiments, we tested the effectiveness of 20 $\mathrm{Hz}$ induced response recovery immediately after a $10 \mathrm{~min}$ Tris wash out and compared this recovery to responses seen after the prolonged presence of Tris. Surprisingly, even after a 10-minlong rest period in the presence of Tris, synaptic responses only recovered to a level $\sim 40 \%$ of the baseline (Fig. $7 C$ ). This small recovery can be attributed to slow replenishment of RRP vesicles from a reserve pool and also possibly to some leakage of Tris from 
spontaneously fusing vesicles. However, we consider the latter possibility unlikely because, according to our previous estimates, the 10 min time frame would be insufficient for spontaneously endocytosed Tris-buffered vesicles to mix with the RRP (Sara et al., 2005). However, after the exchange of the Tris-containing solution, synaptic responses recovered rapidly and transiently (Fig. 7C). Under these conditions, switching the stimulation frequency to $1 \mathrm{~Hz}$ resulted in a rapid response recovery in parallel to what is seen in control experiments (Fig. 7C).

The interpretation of these results relies on the premise that uptake of Tris into endocytosing synaptic vesicles substantially slows their reacidification and a large number of vesicles can be trapped in a relatively alkaline state for minutes after endocytosis. To test this premise, we used dissociated hippocampal cultures prepared from transgenic mice expressing synaptophluorin, which reports the extent of vesicle acidification after endocytosis, predominantly within excitatory synapses (Li et al., 2005). Stimulation of these cultures at $20 \mathrm{~Hz}$ for $10 \mathrm{~s}$ in the presence of an extracellular solution buffered with 100 mM Tris (in our estimates, fully suppresses vesicle refilling) resulted in a rapid increase in fluorescence, which exhibited a slow decrease even after wash out of Triscontaining solution for $10 \mathrm{~min}$ (supplemental Fig. $5 A, B$, available at www. jneurosci.org as supplemental material). A second $20 \mathrm{~Hz}, 10 \mathrm{~s}$ stimulation resulted in a smaller increase in fluorescence and a gradual return to near-baseline fluorescence levels consistent with unloading of Tris from fused vesicles (supplemental Fig. $5 A$, available at www.jneurosci.org as supplemental material). This long-term retention of the increase in synaptophluorin fluorescence was in striking contrast to the swift decrease in the same fluorescence level after stimulation without Tris application, consistent with synaptophluorin endocytosis and vesicle reacidification (supplemental Fig. 5B, available at www.jneurosci.org as supplemental material). These results support the premise that high concentrations of Tris can be trapped in endocytosed vesicles and impede vesicle reacidification for minutes after endocytosis. In the same set of experiments, we also tested the effectiveness of other manipulations in impeding synaptic vesicle reacidification after endocytosis (supplemental Fig. $5 B$, available at www.jneurosci.org as supplemental material). Folimycin treatment substantially slowed the rate of reacidification after $20 \mathrm{~Hz}, 10 \mathrm{~s}$ stimulation, in agreement with previous studies using bafilomycin (Sankaranarayanan and Ryan, 2001). All other manipulations ( $5 \mathrm{mM} \mathrm{NH}_{4} \mathrm{Cl}, 15 \mathrm{~mm}$ HEPES, $15 \mathrm{~mm}$ Tris, $\mathrm{pH}$ 9) significantly slowed the rate of reacidification compared with controls. However, they did not completely alter reacidification as seen with $100 \mathrm{~mm}$ Tris or folimycin treatment. Together with our observation that $\mathrm{pH} 6.5$ is sufficient to impair neurotransmitter refilling, these results indicate that even small
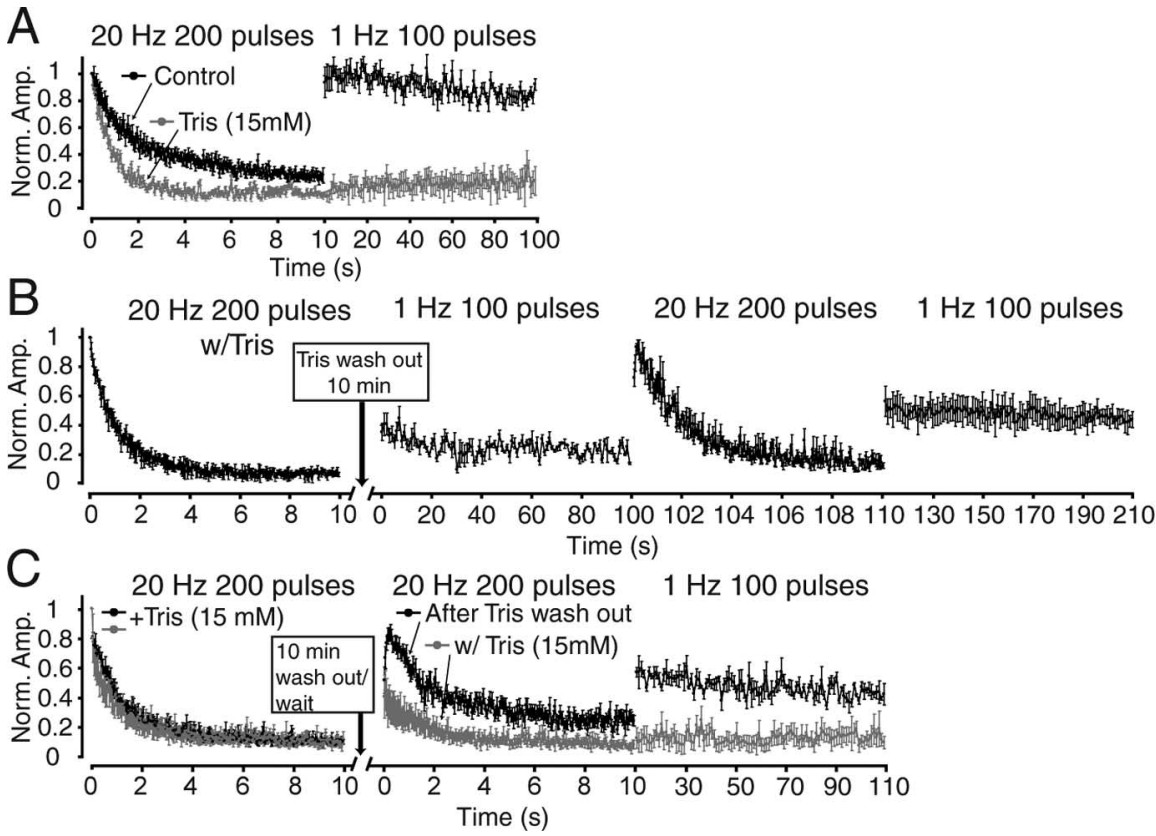

Figure 7. Frequency-dependent recovery from Tris-induced depression. $\boldsymbol{A}$, Plots showing synaptic depression and recovery in the presence or absence of $15 \mathrm{~mm}$ Tris at excitatory synapses. During each experiment, after a train of 200 pulses at $20 \mathrm{~Hz}$, initial response). B, Experiments showing use-dependent recovery from Tris-induced synaptic depression after Tris wash out this set of experiments, after CA1 neurons were patched, slices were perfused with ACSF solution, which contained 15 mm of Tris 列 5 min period, postsynaptic responses evoked by $20 \mathrm{~Hz} 200$ pulses of focal electrical stimulation were out, electrical stimulation at $1 \mathrm{~Hz}$ frequency revealed very little response recovery for $100 \mathrm{~s}$. However, when the stimulation

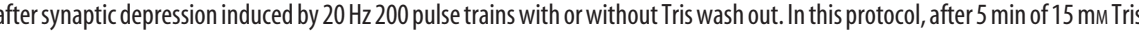
of their initial response within the first $200 \mathrm{~ms}$ and subsequently depressed rapidly in contrast to experiments without wash out in which EPSC amplitudes recovered less but subsequently still depressed rapidly.

alterations in synaptic vesicle reacidification can result in substantial changes in the amount of neurotransmitter uptake. In addition, it is important to note that glutamate uptake relies on the electrical gradient across the vesicle membrane rather than the $\mathrm{pH}$ gradient (Maycox et al., 1988). Thus, some of our manipulations, including the changes in $\mathrm{Na}^{+}$concentration, may modify the voltage across the vesicle membrane more than the $\mathrm{pH}$ gradient per se. Therefore, in interpreting the results of these experiments we cannot fully exclude the possibility that the longterm reversible inhibition of neurotransmitter refilling may be a nonspecific effect of Tris, independent of its $\mathrm{pH}$ buffering.

\section{Kinetic correspondence between the time courses of uptake and release of Tris from rapidly reused vesicles}

These findings can be explained by the uptake of the small $\mathrm{pH}$ buffer Tris into synaptic vesicles during high-frequency synaptic activity when high concentrations of Tris are present in the extracellular medium. If this premise were correct then one would expect to see a kinetic correspondence between the time courses of uptake and release of Tris from rapidly reused vesicles. Indeed, when we aligned the kinetics of Tris-induced depression (the difference between $20 \mathrm{~Hz}$-induced depression with and without 

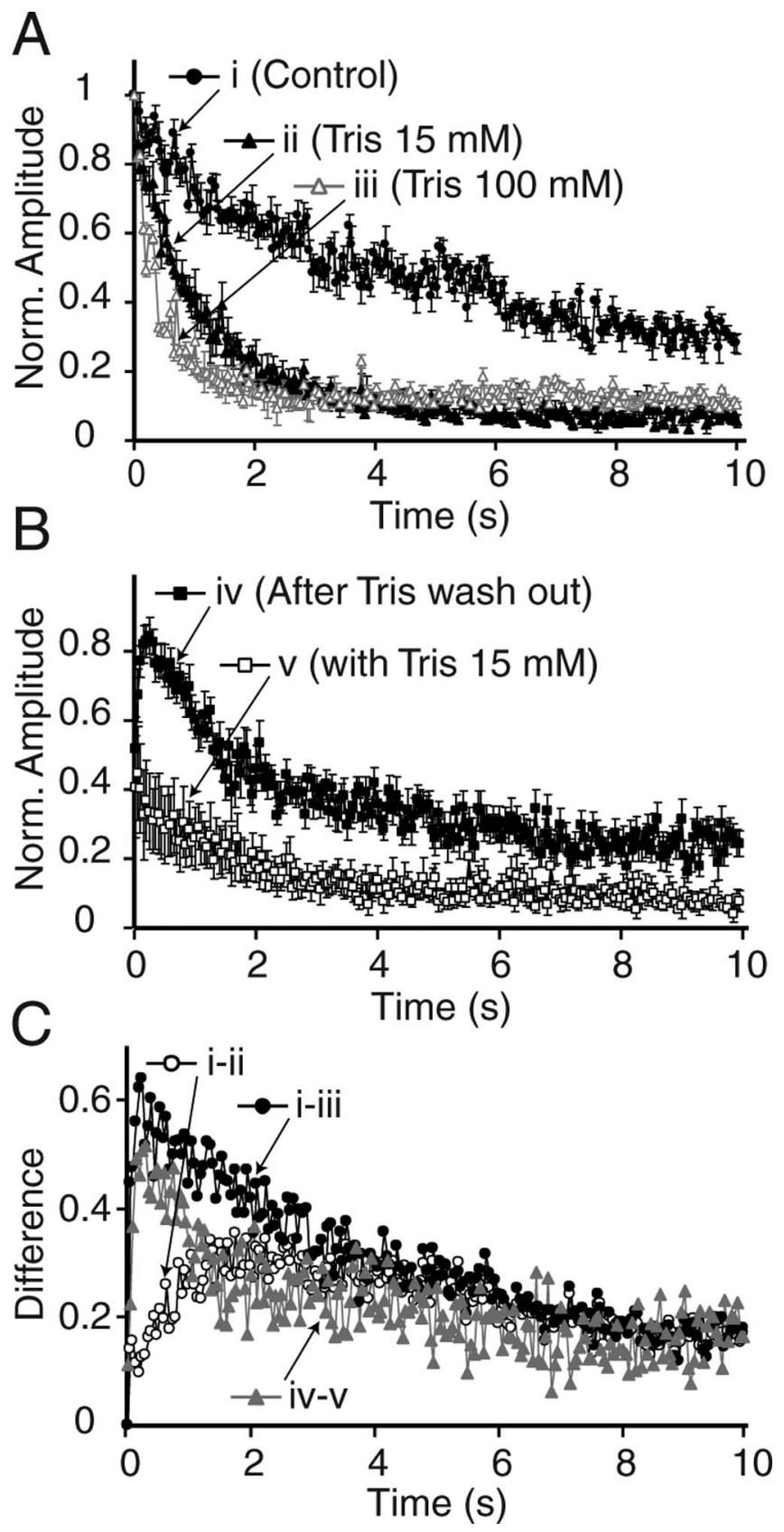

Figure 8. The kinetics of use-dependent recovery from depression matches the difference between synaptic depression kinetics recorded under control and Tris-treated conditions. $\boldsymbol{A}$, Plots showing $20 \mathrm{~Hz}$ - (200 pulses) induced synaptic depression in control, $15 \mathrm{~mm}$ Tris-, and 100 mm Tris-treated slices. $\boldsymbol{B}$, Plots showing the recovery after $20 \mathrm{~Hz}$, 200 pulse trains in the presence or absence of Tris. C, Plots showing three curves depicting the difference in synaptic depression kinetics between control and $15 \mathrm{~mm}$ Tris (i-ii), control, and $100 \mathrm{~mm}$ Tris (i-iii), and $20 \mathrm{~Hz}$-induced response recovery with and without Tris wash out (iv-v). Note the match between curves i-iii and iv-v. This analysis is performed on the data presented in Figures 6 and 7.

Tris) (Fig. $8 \mathrm{~A}$ ) and use-dependent response recovery from Trisinduced depression (the difference between $20 \mathrm{~Hz}$-induced response recovery with and without Tris wash out) (Fig. $8 \mathrm{~B}$ ), we detected significant parallels in the onset of the two curves, although the response recovery was more robust than the depression kinetics (Fig. 8C). The match between the two processes increased further when we used depression kinetics induced by $100 \mathrm{~mm}$ extracellular Tris instead of $15 \mathrm{~mm}$ Tris, indicating that $\mathrm{pH}$ buffering and blockade of neurotransmitter refilling induced by $15 \mathrm{~mm}$ Tris is not maximal whereas loss of Tris from vesicles after fusion was nearly complete. Together, this analysis reveals a significant internal consistency in experiments using small $\mathrm{pH}$ buffers to monitor synaptic vesicle reuse electrophysiologically.

\section{A simple kinetic scheme can account for the frequency dependence of synaptic vesicle reuse}

Our experiments so far support a scenario in which synaptic vesicle reuse contributes to neurotransmission in a frequencydependent manner. To account for our measurements at different frequencies with a single model, we plotted the difference between folimycin-treated and control depression profiles at 1 , 10, 20, and $30 \mathrm{~Hz}$ stimulations (data from Figs. 1, 2) with respect to the number of action potentials for excitatory and inhibitory synapses (Fig. 9B-I, circles). Our results suggest that these difference plots are proportional to the extent of vesicle reuse at each frequency. The difference between folimycin-treated and control traces rises slowly at $1 \mathrm{~Hz}$ and is sustained throughout the duration of stimulation (Fig. 9B,C). In contrast, the difference between the two depression profiles displays a more transient nature at high frequencies (Fig. 9H,I). We developed a simple model with three states connected by frequency-dependent rate constants to fit these data (Fig. 9A). In this model, the transition rates between the states ( $\alpha$ and $\beta$ ) depend on stimulation frequency. This frequency dependence may arise from changes in intrasynaptic $\mathrm{Ca}^{2+}$ or the amount of vesicle fusion (the number of vesicles fused and to be retrieved). According to this model, synapses initially occupy the "rest" state and transition to the "reuse" state in response to stimulation. The rate constant " $\alpha$ " from the rest to the reuse state can be taken as an upper bound for the rate that the initial set of vesicles are reused after stimulation onset. Once in the reuse state, synapses transition into a state of "exhaustion" with a rate of $\beta$ in which synaptic vesicles cease to be reused rapidly, presumably because of saturation or depletion of the endocytic machinery that sustains rapid reuse (Sankaranarayanan and Ryan, 2001). In Figure 9, solid lines depict the progression of the reuse state during stimulation estimated by fitting the model to the data by minimizing the mean square of the error. In the case of excitatory synapses, the rates $\alpha$ and $\beta$ increase monotonically in response to the increase in the frequency of stimulation (Fig. 9J). In inhibitory synapses, the same rates plateau after $10 \mathrm{~Hz}$ (Fig. 9K). In both types of synapses, at $1 \mathrm{~Hz}$, the reuse state appears to dominate at steady state when $\alpha$ and $\beta$ are low. As stimulation frequency increases, the onset of reuse gets faster and the synapses rapidly transition into the exhaustion state, thus limiting fast reuse to a transient period. This simple model satisfies the minimum requirements to account for the data presented in this study. In addition, frequency-dependent activation (rest $\rightarrow$ reuse) and inactivation (reuse $\rightarrow$ exhaustion) of synaptic vesicle reuse may potentially reconcile our results with previous observations (Harata et al., 2006b). It is also possible to extend this model and include a second set of states with slower rates of transition between the states (a slow reuse mode). This extended model can account for our previous finding that in hippocampal synapses synaptic vesicles can be reused under strong sustained stimulation at steady state, albeit with a slower rate (Sara et al., 2002). It is important to note that in different synapses, vesicle reuse may have different frequency dependence characteristics and, moreover, these characteristics may shift in response to extrinsic factors such as chronic levels of network activity (Virmani et al., 2006). 
A

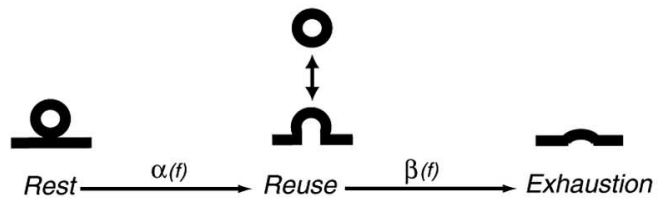

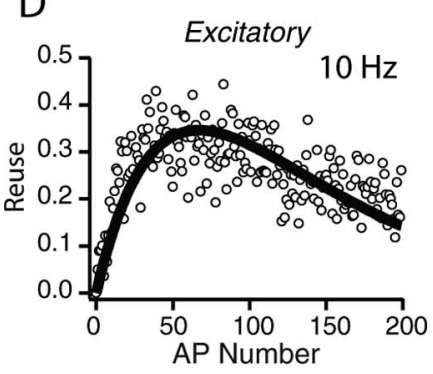

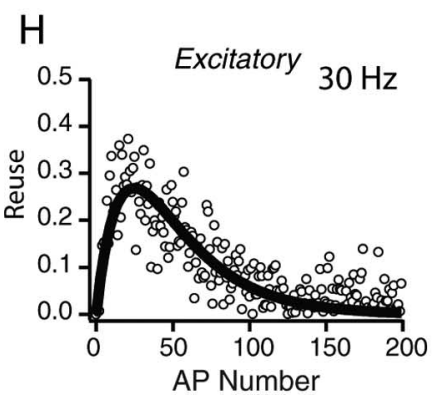

$\mathrm{E}$

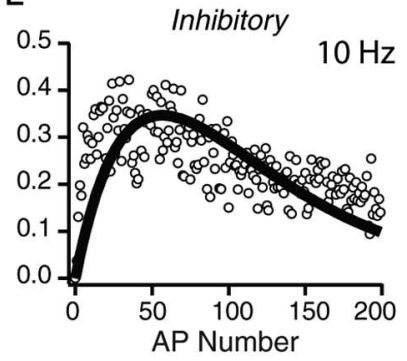

1

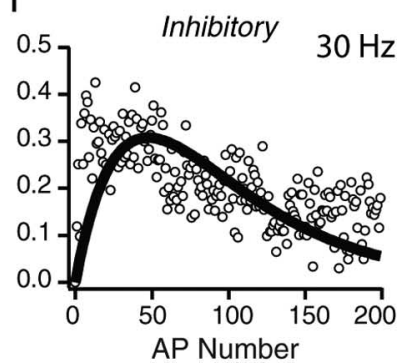

B

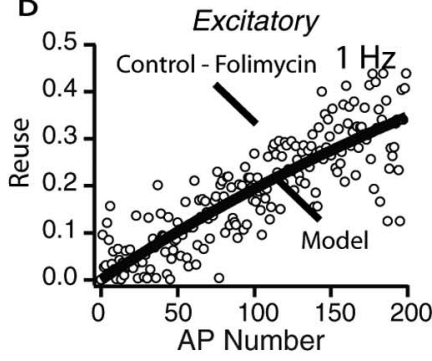

$\mathrm{F}$

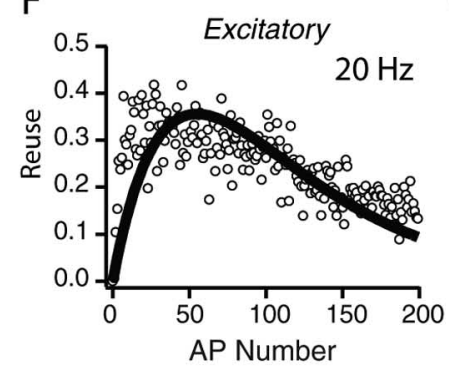

G

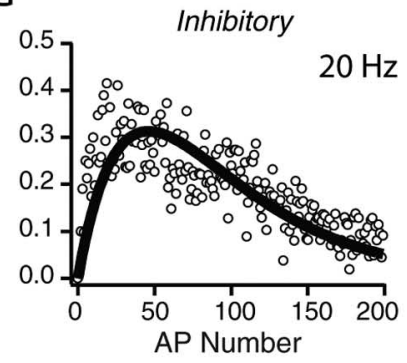

K

J

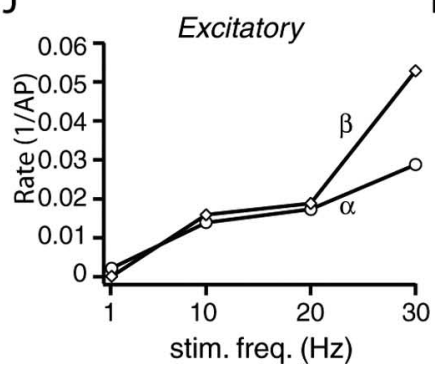

C

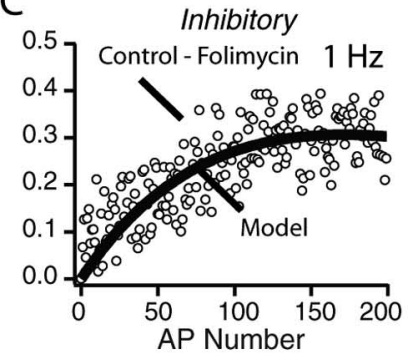

Figure 9. A simple model for the frequency dependence of synaptic vesicle reuse. $A$, The figure depicts the kinetic model we used to account for our observations. In this model, synapses initially occupy the "rest" state and transition to the "reuse" state in response to stimulation with a rate $\alpha$. Synapses transition from the reuse state to a state of "exhaustion" with a rate $\beta$. The transition rates between the states $(\alpha$ and $\beta$ ) depend on stimulation frequency. $\boldsymbol{B}-\boldsymbol{I}$, The difference between folimycin-treated and control depression profiles at 1 , 10 , 20 , and $30 \mathrm{~Hz}$ stimulations (data from Figs. 1, 2) plotted with respect to the number of action potentials for excitatory $(\boldsymbol{B}, \boldsymbol{D}, \boldsymbol{F}, \boldsymbol{H})$ and inhibitory $(\boldsymbol{C}, \boldsymbol{E}, \boldsymbol{G}, \boldsymbol{I})$ synapses (open circles). Solid lines depict the progression of the reuse state during stimulation estimated by fitting the model to the data by minimizing the mean square of the error. The occupancy of reuse state was calculated by solving the following first-order equations: $d($ rest $) / d n=-\alpha$ (rest), $d$ (reuse) $/ d n=\alpha$ (rest) $-\beta$ (reuse), and $d$ (exhaustion) $/ d n=\beta$ (reuse), where $n$ denotes the number of action potentials. J, In the case of excitatory synapses, the rates $\alpha$ and $\beta$ increase monotonically in response to the increase in the frequency of stimulation. $\boldsymbol{K}$, In inhibitory synapses, the same rates plateau after $10 \mathrm{~Hz}$.

\section{Discussion}

In this study, we used a predominantly electrophysiological approach to examine the properties of synaptic vesicle reuse and its impact on short-term synaptic depression in the CA1 region of the hippocampus. We took advantage of multiple maneuvers to manipulate the $\mathrm{pH}$ gradient across the synaptic vesicle membranes to impair neurotransmitter refilling after endocytosis. The electrophysiological nature of our approach enabled rapid detection of vesicle reuse kinetics and a direct relationship between synaptic vesicle recycling and short-term synaptic depression. This approach provided information difficult to attain by optical methods or by comparison of optical and electrical measures (Virmani et al., 2006). These manipulations did not impair fusion as judged by paired-pulse ratios, FM dye destaining kinetics, and their use dependence. Postsynaptic receptor properties also were unaffected by these maneuvers as the amplitudes of mEPSCs and mIPSCs were unchanged. These experiments revealed that at frequencies $>10 \mathrm{~Hz}$, vesicles resident within the RRP are rapidly used and reused to sustain the diminishing level of neurotransmission. Interestingly, in the absence of neurotransmitter refilling, synaptic responses depressed within $2 \mathrm{~s}$, suggesting minimal contribution of a reserve pool of vesicles to neurotransmission at these frequencies.
It is rather surprising that small $\mathrm{pH}$ buffers caused only slow depression at low stimulation frequencies such as 0.1 and $1 \mathrm{~Hz}$, whereas in response to high-frequency stimulation they depress transmission rapidly. We interpret this finding in terms of frequency dependence of vesicle reuse. A simple kinetic model presented in Figure 9, where synapses rapidly transition into a state of vesicle reuse in a frequency-dependent manner, supports this interpretation. At high frequencies, the lifetime of synapses in the reuse state is limited by an inactivating mechanism, which may be attributable to exhaustion of the endocytic machinery required to sustain this rapid form of recycling. Together, this model suggests that vesicle reuse dominates at steady state at low frequencies but at high frequencies it is active in a rather transient manner after the initial onset of stimulation. This model can be extended with the addition of a second set of states to include a slow reuse pathway. This extended model may incorporate our previous finding that, under strong sustained stimulation, hippocampal synapses are still capable of vesicle reuse albeit with a slower rate (Sara et al., 2002).

In the absence of a substantial contribution of a reserve pool, how can release be sustained so stably at low frequencies? One possible answer to this paradox comes from the recent observations of Harata et al. (2006a) that at low frequencies, fusion pore 
openings are limited in size to impair exchange of small molecules. At high frequencies, larger fusion pore openings enable easy access of small molecules such as Tris and HEPES to the vesicle interior. However, this explanation is inconsistent with the effect of folimycin because in these experiments, protons are the only necessary ions crossing the pore, which are not expected to be limited with even the smallest fusion pore size. Therefore, we surmise that the fusion pore does not appear to present a significant impediment to diffusion of small $\mathrm{pH}$ buffers. In contrast, we propose an alternative scenario in which, at high frequencies, a mechanism other than vesicle depletion causes depression [e.g., a refractory period (Dobrunz et al., 1997) or inactivation of voltage-gated $\mathrm{Ca}^{2+}$ channels (Xu and $\left.\mathrm{Wu}, 2005\right)$ ] and this process is not rate limiting at low frequencies. According to this scenario, rapid synaptic vesicle reuse is activated at this frequency range to maintain neurotransmission, thus balancing depression caused by factors other than vesicle depletion. However, it is also possible that the two frequency regimes $(0.1-1 \mathrm{~Hz}$ vs $10-30 \mathrm{~Hz}$ ) recruit separate sets of vesicles with different recycling properties (Vanden Berghe and Klingauf, 2006), which would make the mechanisms governing synaptic depression at these two frequency ranges harder to reconcile in a single scheme.

Our findings in the CA1 region of the hippocampus are consistent with several previous observations. For instance, optical experiments using uptake and release of styryl dyes in acute hippocampal slices showed that RRP vesicles labeled with FM1-43 using hypertonic sucrose application did not readily mix with the reserve pool vesicles labeled with strong high-potassium stimulation up to $2 \mathrm{~h}$ (Stanton et al., 2005). This previous finding is in line with our observation that reserve pool vesicles do not significantly contribute to neurotransmission at high frequencies. Preferential recycling of RRP vesicles back to their pool of origin have been observed in dissociated hippocampal cultures (Pyle et al., 2000; Sara et al., 2002) as well as in cortical synaptosomes obtained from adult rats brains (Ashton and Ushkaryov, 2005). In addition, endocytosis gets accelerated with $\mathrm{Ca}^{2+}$ influx in the calyx of Held terminal in the auditory brainstem (Wu et al., 2005) as well as in dissociated hippocampal cultures (Sankaranarayanan and Ryan, 2001), presumably to support rapid reuse of at least some of the RRP vesicles (but see Li et al., 2005; Zenisek, 2005). However, in contrast to our observations in acute hippocampal slices, RRP vesicles in most other preparations readily mix with a reserve pool over time (Pyle et al., 2000; de Lange et al., 2003). Interestingly, recent studies in the cone photoreceptor terminals (Rea et al., 2004) or in snake motor nerve terminals (Lin et al., 2005) revealed a more streamlined vesicle recycling consistent with a single functional pool of vesicles. Moreover, RRP vesicles in the frog neuromuscular junction also follow a rather isolated recycling pathway and only mix with a reserve pool after very strong and sustained stimulation (Richards et al., 2003; Rizzoli and Betz, 2005). Therefore, the exclusive recycling of RRP vesicles in hippocampal slices may reflect a more widespread facet of synaptic vesicle trafficking and its presence or absence may be dictated by the activity-dependent use history of a particular synapse (Virmani et al., 2006).

The ultra-rapid kinetics of synaptic vesicle reuse implied by our results is also consistent with some previous findings that used genetic methods to address the same question. For instance, in the Drosophila neuromuscular junction at nonpermissive temperatures, the shibire mutation leads to inactivation of dynamin causing use-dependent depression of neurotransmission under repetitive stimulation similar to what we see in this study (Delgado et al., 2000). The rapid nature of this depression has been a puzzling aspect of this mutant, and in some studies this fast decrease in exocytosis has been attributed to the block of fusion by stranded vesicles or a potential role of dynamin in fusion rather than loss of rapid vesicle reuse (Kawasaki et al., 2000). However, recent evidence from the calyx of Held and other preparations suggests that block of endocytosis has no immediate effect on exocytosis (Mozhayeva et al., 2004; Yamashita et al., 2005; Newton et al., 2006). The maneuvers we used in this study do not interfere with endocytosis. The data presented here is consistent with previous work showing that interference with neurotransmitter refilling and/or vesicle reacidification does not alter synaptic vesicle recycling (Zhou et al., 2000; Sankaranarayanan and Ryan, 2001; Sara et al., 2005). Therefore, it will be interesting to re-examine the shibire mutants for potential evidence of ultrarapid synaptic vesicle reuse.

In summary, our results suggest a tight link between the kinetics of synaptic vesicle reuse and short-term synaptic plasticity occurring within the time scale of hundreds of milliseconds. These results show that rapid vesicle reuse provides a viable mechanism to increase neurotransmitter output in the face of demand in addition to the well documented mechanisms such as neurotransmitter spillover from multiple release sites (Telgkamp et al., 2004). The prevalence of multivesicular release in several types of central synapses may also be a critical factor, which could place significant demands on vesicle supply (Wadiche and Jahr, 2001; Foster et al., 2005; Christie and Jahr, 2006). Therefore, it will be interesting to use the approach we outlined in this study to probe the dynamics of vesicle recycling in other brain regions with rapid time resolution.

\section{References}

Aravanis AM, Pyle JL, Tsien RW (2003) Single synaptic vesicles fusing transiently and successively without loss of identity. Nature 423:643-647.

Ashton AC, Ushkaryov YA (2005) Properties of synaptic vesicle pools in mature central nerve terminals. J Biol Chem 280:37278-37288.

Atluri PP, Ryan TA (2006) The kinetics of synaptic vesicle reacidification at hippocampal nerve terminals. J Neurosci 26:2313-2320.

Betz WJ, Bewick GS (1992) Optical analysis of synaptic vesicle recycling at the frog neuromuscular junction. Science 255:200-203.

Betz WJ, Bewick GS (1993) Optical monitoring of transmitter release and synaptic vesicle recycling at the frog neuromuscular junction. J Physiol (Lond) 460:287-309.

Christie JM, Jahr CE (2006) Multivesicular release at Schaffer collateralCA1 hippocampal synapses. J Neurosci 26:210-216.

de Lange RP, de Roos AD, Borst JG (2003) Two modes of vesicle recycling in the rat calyx of Held. J Neurosci 23:10164-10173.

Delgado R, Maureira C, Oliva C, Kidokoro Y, Labarca P (2000) Size of vesicle pools, rates of mobilization, and recycling at neuromuscular synapses of a Drosophila mutant, shibire. Neuron 28:941-953.

Diamond JS, Jahr CE (1997) Transporters buffer synaptically released glutamate on a submillisecond time scale. J Neurosci 17:4672-4687.

Dobrunz LE, Huang EP, Stevens CF (1997) Very short-term plasticity in hippocampal synapses. Proc Natl Acad Sci USA 94:14843-14847.

Drose S, Altendorf K (1997) Bafilomycins and concanamycins as inhibitors of V-ATPases and P-ATPases. J Exp Biol 200 (Pt 1):1-8.

Fernandez-Alfonso T, Ryan TA (2004) The kinetics of synaptic vesicle pool depletion at CNS synaptic terminals. Neuron 41:943-953.

Fernandez-Alfonso T, Kwan R, Ryan TA (2006) Synaptic vesicles interchange their membrane proteins with a large surface reservoir during recycling. Neuron 51:179-186.

Fonnum F, Fykse EM, Roseth S (1998) Uptake of glutamate into synaptic vesicles. Prog Brain Res 116:87-101.

Foster KA, Crowley JJ, Regehr WG (2005) The influence of multivesicular release and postsynaptic receptor saturation on transmission at granule cell to Purkinje cell synapses. J Neurosci 25:11655-11665.

Gandhi SP, Stevens CF (2003) Three modes of synaptic vesicular recycling revealed by single-vesicle imaging. Nature 423:607-613.

Granseth B, Odermatt B, Royle SJ, Lagnado L (2006) Clathrin-mediated 
endocytosis is the dominant mechanism of vesicle retrieval at hippocampal synapses. Neuron 51:773-786.

Harata N, Pyle JL, Aravanis AM, Mozhayeva M, Kavalali ET, Tsien RW (2001) Limited numbers of recycling vesicles in small CNS nerve terminals: implications for neural signaling and vesicular cycling. Trends Neurosci 24:637-643.

Harata NC, Choi S, Pyle JL, Aravanis AM, Tsien RW (2006a) Frequencydependent kinetics and prevalence of kiss-and-run and reuse at hippocampal synapses studied with novel quenching methods. Neuron 49:243-256.

Harata NC, Aravanis AM, Tsien RW (2006b) Kiss-and-run and fullcollapse fusion as modes of exo-endocytosis in neurosecretion. J Neurochem 97:1546-1570.

Kavalali ET, Klingauf J, Tsien RW (1999) Activity-dependent regulation of synaptic clustering in a hippocampal culture system. Proc Natl Acad Sci USA 96:12893-12900.

Kawasaki F, Hazen M, Ordway RW (2000) Fast synaptic fatigue in shibire mutants reveals a rapid requirement for dynamin in synaptic vesicle membrane trafficking. Nat Neurosci 3:859-860.

Klingauf J, Kavalali ET, Tsien RW (1998) Kinetics and regulation of fast endocytosis at hippocampal synapses. Nature 394:581-585.

Li Z, Murthy VN (2001) Visualizing postendocytic traffic of synaptic vesicles at hippocampal synapses. Neuron 31:593-605.

Li Z, Burrone J, Tyler WJ, Hartman KN, Albeanu DF, Murthy VN (2005) Synaptic vesicle recycling studied in transgenic mice expressing synaptopHluorin. Proc Natl Acad Sci USA 102:6131-6136.

Lin MY, Teng H, Wilkinson RS (2005) Vesicles in snake motor terminals comprise one functional pool and utilize a single recycling strategy at all stimulus frequencies. J Physiol (Lond) 568:413-421.

Maximov A, Sudhof TC (2005) Autonomous function of synaptotagmin 1 in triggering synchronous release independent of asynchronous release. Neuron 48:547-554.

Maycox PR, Deckwerth T, Hell JW, Jahn R (1988) Glutamate uptake by brain synaptic vesicles. Energy dependence of transport and functional reconstitution in proteoliposomes. J Biol Chem 263:15423-15428.

Miesenbock G, De Angelis DA, Rothman JE (1998) Visualizing secretion and synaptic transmission with $\mathrm{pH}$-sensitive green fluorescent proteins. Nature 394:192-195.

Moriyama Y, Futai M (1990) H(+)-ATPase, a primary pump for accumulation of neurotransmitters, is a major constituent of brain synaptic vesicles. Biochem Biophys Res Commun 173:443-448.

Moulder KL, Mennerick S (2005) Reluctant vesicles contribute to the total readily releasable pool in glutamatergic hippocampal neurons. J Neurosci 25:3842-3850.

Mozhayeva MG, Matos MF, Liu X, Kavalali ET (2004) Minimum essential factors required for vesicle mobilization at hippocampal synapses. J Neurosci 24:1680-1688.

Murthy VN, Stevens CF (1999) Reversal of synaptic vesicle docking at central synapses. Nat Neurosci 2:503-507.

Newton AJ, Kirchhausen T, Murthy VN (2006) Inhibition of dynamin completely blocks compensatory synaptic vesicle endocytosis. Proc Natl Acad Sci USA 103:17955-17960.

Pyle JL, Kavalali ET, Piedras-Renteria ES, Tsien RW (2000) Rapid reuse of readily releasable pool vesicles at hippocampal synapses. Neuron 28:221-231.

Rea R, Li J, Dharia A, Levitan ES, Sterling P, Kramer RH (2004) Streamlined synaptic vesicle cycle in cone photoreceptor terminals. Neuron 41:755-766.

Richards DA, Guatimosim C, Rizzoli SO, Betz WJ (2003) Synaptic vesicle pools at the frog neuromuscular junction. Neuron 39:529-541.

Richards DA, Bai J, Chapman ER (2005) Two modes of exocytosis at hippocampal synapses revealed by rate of FM1-43 efflux from individual vesicles. J Cell Biol 168:929-939.

Rizzoli SO, Betz WJ (2005) Synaptic vesicle pools. Nat Rev Neurosci 6:57-69.

Rosenmund C, Stevens CF (1996) Definition of the readily releasable pool of vesicles at hippocampal synapses. Neuron 16:1197-1207.

Roseth S, Fykse EM, Fonnum F (1995) Uptake of L-glutamate into rat brain synaptic vesicles: effect of inhibitors that bind specifically to the glutamate transporter. J Neurochem 65:96-103.

Sankaranarayanan S, Ryan TA (2001) Calcium accelerates endocytosis of vSNAREs at hippocampal synapses. Nat Neurosci 4:129-136.

Sara Y, Mozhayeva MG, Liu X, Kavalali ET (2002) Fast vesicle recycling supports neurotransmission during sustained stimulation at hippocampal synapses. J Neurosci 22:1608-1617.

Sara Y, Virmani T, Deak F, Liu X, Kavalali ET (2005) An isolated pool of vesicles recycles at rest and drives spontaneous neurotransmission. Neuron 45:563-573.

Stanton PK, Winterer J, Zhang XL, Muller W (2005) Imaging LTP of presynaptic release of FM1-43 from the rapidly recycling vesicle pool of Schaffer collateral-CA1 synapses in rat hippocampal slices. Eur J Neurosci 22:2451-2461.

Sudhof TC (2000) The synaptic vesicle cycle revisited. Neuron 28:317-320.

Telgkamp P, Padgett DE, Ledoux VA, Woolley CS, Raman IM (2004) Maintenance of high-frequency transmission at purkinje to cerebellar nuclear synapses by spillover from boutons with multiple release sites. Neuron 41:113-126.

Vanden Berghe P, Klingauf J (2006) Synaptic vesicles in rat hippocampal boutons recycle to different pools in a use-dependent fashion. J Physiol (Lond) 572:707-720.

Virmani T, Atasoy D, Kavalali ET (2006) Synaptic vesicle recycling adapts to chronic changes in activity. J Neurosci 26:2197-2206.

Wadiche JI, Jahr CE (2001) Multivesicular release at climbing fiberPurkinje cell synapses. Neuron 32:301-313.

Wienisch M, Klingauf J (2006) Vesicular proteins exocytosed and subsequently retrieved by compensatory endocytosis are nonidentical. Nat Neurosci 9:1019-1027.

Wu W, Xu J, Wu XS, Wu LG (2005) Activity-dependent acceleration of endocytosis at a central synapse. J Neurosci 25:11676-11683.

Xie XS, Padron D, Liao X, Wang J, Roth MG, De Brabander JK (2004) Salicylihalamide A inhibits the V0 sector of the V-ATPase through a mechanism distinct from bafilomycin A1. J Biol Chem 279:19755-19763.

Xu J, Wu LG (2005) The decrease in the presynaptic calcium current is a major cause of short-term depression at a calyx-type synapse. Neuron 46:633-645.

Yamashita T, Hige T, Takahashi T (2005) Vesicle endocytosis requires dynamin-dependent GTP hydrolysis at a fast CNS synapse. Science 307:124-127.

Zenisek D (2005) Vesicle reuse revisited. Proc Natl Acad Sci USA 102:7407-7408.

Zhou Q, Petersen CC, Nicoll RA (2000) Effects of reduced vesicular filling on synaptic transmission in rat hippocampal neurones. J Physiol (Lond) 525:195-206. 